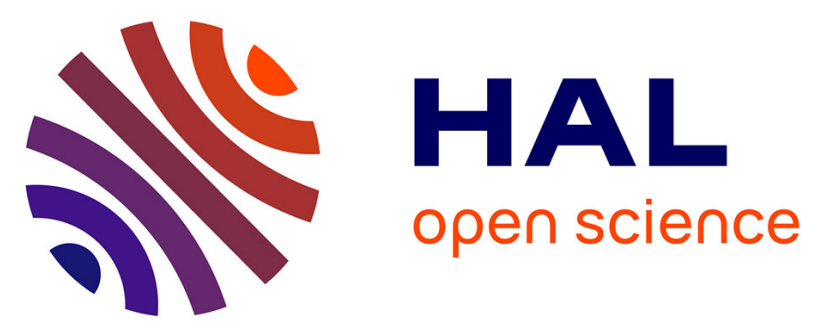

\title{
Collagen suprafibrillar confinement drives the activity of acidic calcium-binding polymers on apatite mineralization
}

\author{
Jérémie Silvent, Marc Robin, Camila Bussola Tovani, Yan Wang, Fabrice
} Soncin, Sidney Delgado, Thierry Azaïs, Capucine Sassoye, Marie-Madeleine Giraud-Guille, Jean-Yves Sire, et al.

\section{To cite this version:}

Jérémie Silvent, Marc Robin, Camila Bussola Tovani, Yan Wang, Fabrice Soncin, et al.. Collagen suprafibrillar confinement drives the activity of acidic calcium-binding polymers on apatite mineralization. Biomacromolecules, 2021, 22 (7), pp.2802-2814. 10.1021/acs.biomac.1c00206 . hal-03259914v1

\section{HAL Id: hal-03259914 \\ https://hal.sorbonne-universite.fr/hal-03259914v1}

Submitted on 14 Jun 2021 (v1), last revised 10 Jan 2022 (v2)

HAL is a multi-disciplinary open access archive for the deposit and dissemination of scientific research documents, whether they are published or not. The documents may come from teaching and research institutions in France or abroad, or from public or private research centers.
L'archive ouverte pluridisciplinaire HAL, est destinée au dépôt et à la diffusion de documents scientifiques de niveau recherche, publiés ou non, émanant des établissements d'enseignement et de recherche français ou étrangers, des laboratoires publics ou privés. 


\section{Collagen suprafibrillar confinement drives the}

\section{activity of acidic calcium-binding polymers on}

\section{apatite mineralization}

Jérémie Silvent ${ }^{1,2}$, Marc Robin $^{1}$, Camila Bussola Tovani ${ }^{1}$, Yan Wang ${ }^{1}$, Fabrice Soncin ${ }^{3}$, Sidney Delgado $^{2}$, Thierry Azaïs ${ }^{1}$, Capucine Sassoye ${ }^{1}$, Marie-Madeleine Giraud-Guille $^{1}$, Jean-Yves Sire ${ }^{2}$ and Nadine Nassif ${ }^{*}$

${ }^{1}$ CNRS, Sorbonne Université, Collège de France, Laboratoire Chimie de la Matière Condensée de Paris, LCMCP, F-75005 Paris, France.

${ }^{2}$ Sorbonne Université, MNHN, CNRS, EPHE, Institut Systématique Évolution Biodiversité, ISYEB, Equipe Homologies, 75005 Paris, France.

${ }^{3}$ Univ. Lille, CNRS, Institut Pasteur de Lille, UMR 8161 - M3T - Mechanisms of Tumorigenesis and Target Therapies, F-59000 Lille, France.

KEYWORDS: self-assembly, confinement, concentration, biopolymer, mineral 
GRAPHICAL ABSTRACT

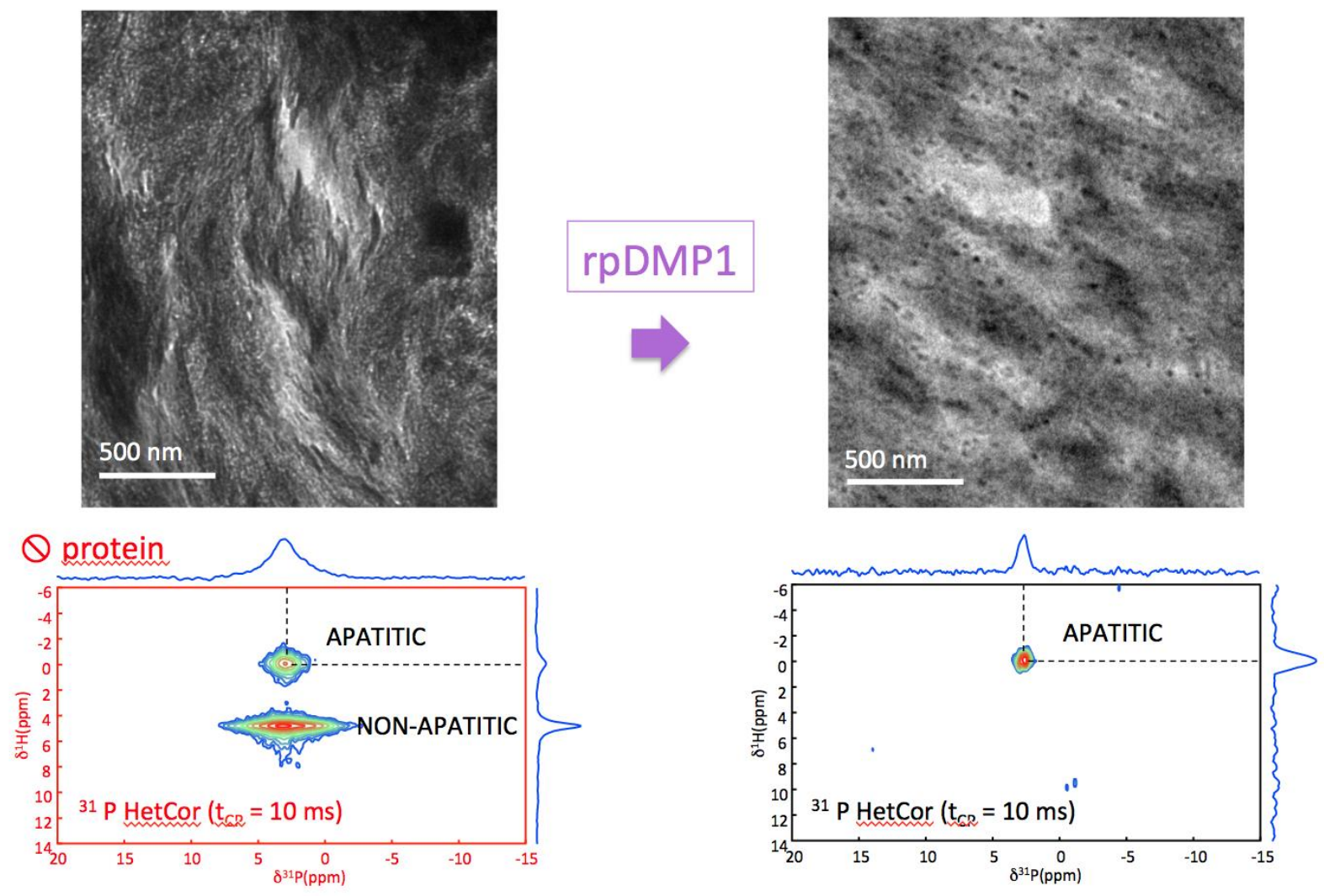




\section{ABSTRACT}

Bone collagenous extracellular matrix provides a confined environment into which apatite crystals form. This biomineralization process is related to a cascade of events partly controlled by noncollagenous proteins. Although overlooked in bone models, concentration and physical environment influence their activities. Here, we show that collagen suprafibrillar confinement in bone comprising intra- and interfibrillar spaces drives the activity of biomimetic acidic calciumbinding polymers on apatite mineralization. The difference in mineralization between a DMP1 recombinant peptide (rpDMP1) and the synthetic polyaspartate validates the specificity of the 57KD fragment of DMP1 in the regulation of mineralization but strikingly without phosphorylation. Besides, we show that all the identified functions of rpDMP1 are dedicated to preclude pathological mineralization. Interestingly, transient apatite phases are only found using high nonphysiological concentration of additives. The possibility to combine biomimetic concentration of both collagen and additives ensures specific chemical interactions and offers perspectives for understanding the role of bone components in mineralization. 


\section{INTRODUCTION}

Bone is a complex composite material, which closely associates cells and an extracellular matrix (ECM). The bone ECM combines various components i.e. collagen, non-collagenous proteins (NCPs), carbonated hydroxyapatite (HA) nanoparticles and water. Although bone is one of the most studied living materials, the exact role of its components, noticeably the organic one, is still debated. Both intra- ${ }^{1,2,3}(\sim 40 \mathrm{~nm})$ and interfibrillar ${ }^{4}(\sim 1.5 \mathrm{~nm})$ spaces in collagen are proposed to be nucleation sites for bone mineral. The interfibrillar confinement generated by the collagen matrix increases as the ECM becomes mineralized thus forming the mature bone (Figure 1A) with the characteristic twisted plywood pattern ${ }^{5}$ (Figure 1B). This suprafibrillar three-dimensional architecture affects the physical properties of the ECM such as mechanical response ${ }^{6,7}$ and microenvironment (e.g. size and spatial distribution of apatite, local hydrated environment of phosphate ions). ${ }^{8}$ In addition, in vitro investigations on NCPs activity have indeed yielded contradictory findings when the protein is studied either in solution or in gel ${ }^{9,10}$. Upon working with gels, loose collagen matrices imply large interfibrillar spaces due to the lack of collagen packing ${ }^{8}$ meaning that bone is only reproduced at the fibril level. ${ }^{11,12}$ Consequently, aside in vivobased experiments, biomimetic models in terms of confinement are needed to ensure that investigations of NCPs activity are conducted under native environment. As demonstration, only models mimicking both collagen density and geometry described for mature bone $(250 \mathrm{mg} / \mathrm{mL})^{8}$ tissues led to the typical apatite/collagen co-alignment (Figure 1C) but noticeably with higher concentrations of calcium ions (Figure 1D, left) than that described in extracellular fluid (ECF)

13. Indeed, simulated body fluid (SBF) failed to produce intrafibrillar mineral; instead, apatite in the form of spherulite was found (Figure 1D, right). This result suggested that Ca-rich proteins from bone ECM concentrate ions in the gap regions. 
To go further on the effect of bone ECM confinement on NCPs activity, we pursue the study by entrapping Dentin Matrix Protein-1 (DMP1), an acidic calcium-binding polymer ${ }^{14}$ within our models. DMP1 is a phosphorylated ECM protein produced by osteocytes and odontoblasts that is commonly accepted as mediator in bone mineralization processes. ${ }^{15-17}$ Indeed, DMP1 knockout mice display defective mineralization of dentin ${ }^{18-21}$ and bone ${ }^{22,23}$ resembling phenotypes observed in human genetic. Interestingly, the role of DMP1 has been investigated in vitro through different models (e.g. in solution ${ }^{24,25}$ adsorbed onto glass plates ${ }^{14,26}$ in gelatin-gel systems, ${ }^{15,27}$ on a TEM grid coated with recombinant spider silks, ${ }^{28}$ with pre-assembled collagen fibrils ${ }^{29,30}$ and with early calcifying bone-like matrix) ${ }^{31}$ reaching the conclusion that the protein could be involved at different levels including in apatite nucleation control ${ }^{27,32}$ and growth inhibition, ${ }^{33}$ in mediating the size of collagen fibrils, ${ }^{29}$ and in stabilizing amorphous calcium phosphate (ACP) phase. ${ }^{33,34}$ To clarify such functional diversity, a DMP1 recombinant peptide (rpDMP1) containing those two collagen binding sites ${ }^{29}$ and the peptide ${ }^{427} \mathrm{SSSQE}^{431}$ was synthesized and used here (unphosphorylated, 121 amino acids, $13 \mathrm{kDa}, \mathrm{pI}=4.14)$ (Figure 1E, down). Indeed, four DMP1 peptides are identified in dentin and bone extracts: (1) the full-length protein, (2) a N-ter fragment of $37 \mathrm{kDa},(3)$ a C-ter fragment of $57 \mathrm{kDa},{ }^{35}$ and (4) a proteoglycan derived from the $\mathrm{N}$-ter fragment and known as DMP1-PG found in rat and mouse. ${ }^{36}$ And importantly, five highly conserved motifs during mammalian evolution were identified including ${ }^{427} \mathrm{SSSQE}^{431}$ suggesting the importance of this acidic peptide for the protein structure and/or function. ${ }^{37}$ Moreover, it was reported that the $57-\mathrm{kDa}$ fragment recapitulates the function of full-length DMP-1 in regulation of mineralization and osteocyte maturation. ${ }^{38}$ Finally, phosphorylation appears to be dedicated to the organization of mineral when there is no collagen fibrillar packing ${ }^{39}$ since both phosphorylated and nonphosphorylated rDMP1 are proposed as apatite nucleators. ${ }^{40}$ 
In addition to the confinement criterion, concentration of protein closer to physiological conditions 41,42 is of importance to access to their native properties. Noticeably, differences in range of concentrations (factor 10 to 100 ) can lead to opposite activities ${ }^{14,15,24,26,29}$ blurring the conclusions.

Besides, to validate the specificity of the 57-KD fragment of DMP1 experiments were also carried out with a synthetic calcium-binding polymer, i.e. the biomimetic poly-l-aspartic acid (polyAsp, $1.2 \mathrm{kDa}, \mathrm{pI}=2.98$ ) (Figure 1E, up) ${ }^{43,44}$ Nowadays, polyAsp is commonly used in biomineralization models for mimicking acidic proteins in biological calcified tissues (nacre, bone, dentin). Especially this polymer is described to allow the intrafibrillar infiltration of both DMP1 ${ }^{45}$ and apatite ion precursors ${ }^{46}$ and consequently the collagen/mineral coalignment. ${ }^{47}$

Here, we show that collagen suprafibrillar confinement drives the activity of acidic calcium-binding polymers on apatite mineralization. The difference in mineralization between rpDMP1 and polyAsp illustrates the specificity of NCPs amino-acids sequence. Under confinement (i.e. intra- and interfibrillar spaces), we show that all the identified functions of rpDMP1 are dedicated for proper calcification to occur namely the collagen/apatite coalignment ${ }^{48,49}$. Indeed, we show that while collagen nucleates apatite, rpDMP1 (i) concentrates the apatite ion precursors locally interfering as a supporting agent for collagen (ii) to induce the formation of a first highly crystalline apatite crystal. In addition, we discard that rpDMP1 stabilizes the possible transient precursors of bioapatite ${ }^{50,51}$ since they only form at high non-physiological concentration of protein. Finally, (iii) we confirm that it inhibits the apatite growth but (iv) also show that it might inhibit the homogeneous nucleation irrespective of confinement. Overall, the work demonstrates that aside cellular and biochemical processes, physico-chemical parameters take part in the control of bone biomineralization. 

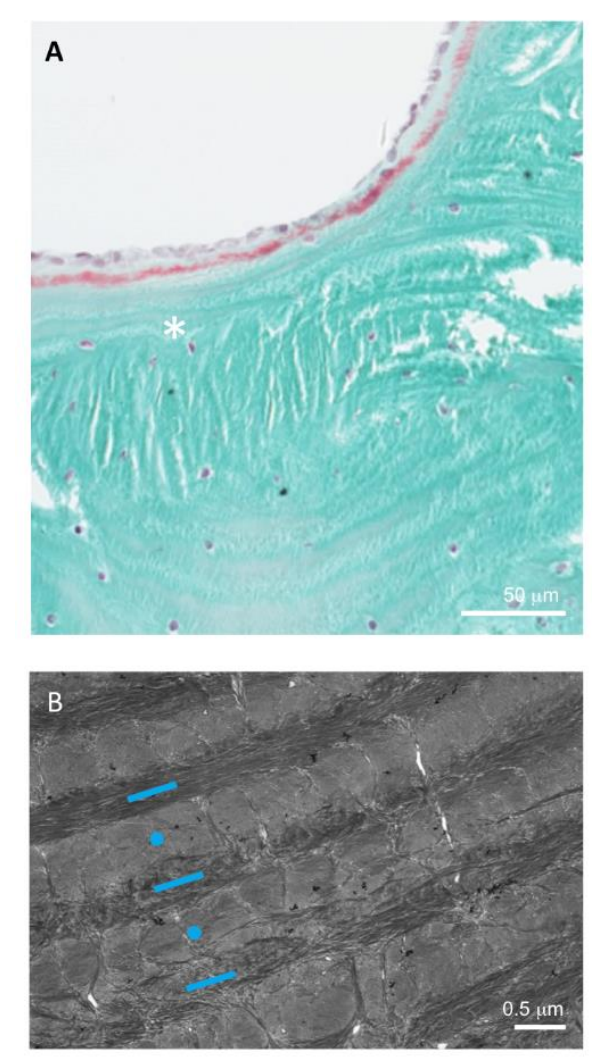

C

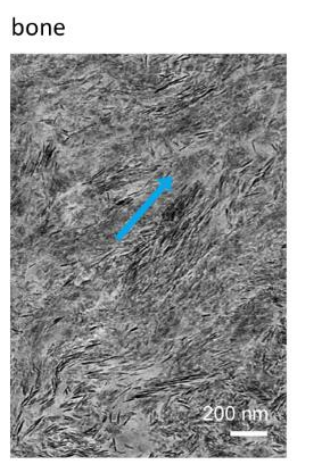

D

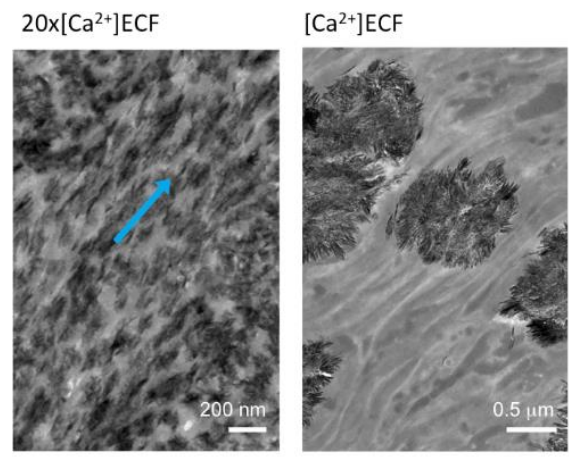

$E$

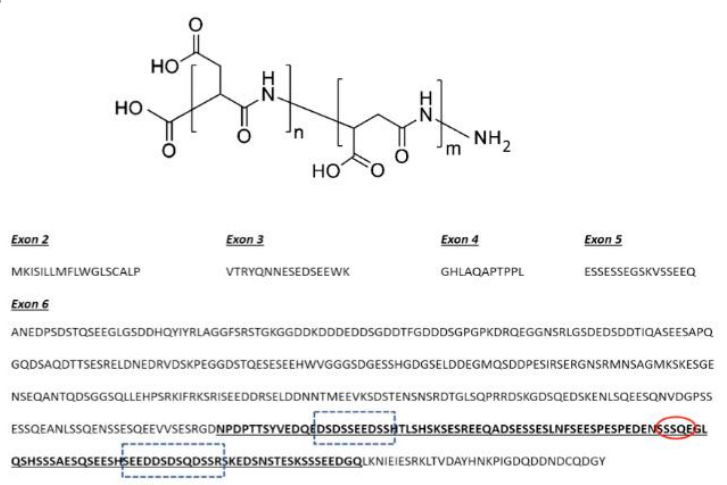

Figure 1. Comparison of collagen/apatite relationship in bone and in synthetic models reproducing the collagen confinement (density and order) found in bone. (A) Thin section of bone stained with Masson's trichrome. From top to bottom: osteoblasts, osteoid tissue (light blue and red) and mature bone (*). Transmission electron microscopy ultrathin sections of (B) mature decalcified human bone that is characterized by a twisted plywood organization of collagen fibrils (blue dot and bars represent molecules that are perpendicular and parallel to the observation plan, respectively) schematically represented, (C) unstained sheep bone where the alignment of apatite platelets along the fibril is observed (the blue arrow shows the orientation), (D) Coll/CHA/SBF (left) and Coll/SBF/SBF (right) where $\left[\mathrm{Ca}^{2+}\right]=20\left[\mathrm{Ca}^{2+}\right] \mathrm{ECF}$ (ExtraCellular Fluid) and $\left[\mathrm{Ca}^{2+}\right]=\left[\mathrm{Ca}^{2+}\right] \mathrm{ECF}$, respectively. The collagen/apatite co-alignment similar to that in bone is observed in Coll/CHA/SBF (left) while spherulitic apatite crystals are obtained in Coll/SBF/SBF (right). In (E), the acidic calcium-polymer used in the biomimetic model, i.e. the polyaspartate formula and the human DMP1 sequence (in bold: target peptide; blue boxed texts: collagen binding sites; red encircled text: motif found as unchanged during $220 \mathrm{My}$ ). The influence of organic polymers on apatite formation is studied at fixed physiological concentration of calcium i.e. $\left[\mathrm{Ca}^{2+}\right]=\left[\mathrm{Ca}^{2+}\right] \mathrm{ECF}$ with two different concentrations for rpDMP1 as follows: $2.5 \mu \mathrm{g} / \mathrm{mL}$ (1rpDMP1) and $25 \mu \mathrm{g} / \mathrm{mL}$ (10rpDMP1). 
MATERIALS AND METHODS

\section{Synthesis and purification of the recombinant DMP1 peptide.}

Cloning. The coding sequence of our targeted human DMP1 peptide (i.e. amino acids 367-481) was isolated from a human primary osteoblast cDNA (Promocell@). It was amplified in a thermal cycler (Mastercycler pro, Eppendorf) by PCR using the oligonucleotides 5' ATGC CATATG AACCCCGACCCCA 3' and 5' GCAT CTCGAGTCA GTG GTG GTG GTG GTG GTG GTG CAACTGGCCATCTTC 3'to create NdeI and XhoI restriction sites at the start and stop codon, respectively. Cycling conditions were initial denaturation at $94^{\circ} \mathrm{C}$ for $2 \mathrm{~min}$, followed by 35 cycles, each cycle consisting of $30 \mathrm{sec}$ of denaturation at $94^{\circ} \mathrm{C}, 45 \mathrm{sec}$ of annealing at $60^{\circ} \mathrm{C}$ and $45 \mathrm{sec}$ of elongation at $72^{\circ} \mathrm{C}$. The final elongation lasted for 2 min at $72^{\circ} \mathrm{C}$. PCR products were analyzed by $1 \%$ agarose gel electrophoresis and observed in an analyzer Gel Doc (BIORAD, France) after ethidium bromide staining. The amplified fragment was purified using the QIAquick PCR purification kit (Qiagen SA), and digested with NdeI and XhoI restriction enzymes. The resulting products were separated by a migration in a $1.5 \%$ agarose gel with ethidium bromide and cloned into the pET22b vector (Novagen/VWR International S.A.S) which had been beforehand digested similarly. Competent Novablue cells were transformed with the ligation mix, and selected by overnight growth on LB agarose plates containing $70 \mu \mathrm{g} / \mathrm{ml}$ ampicillin. Positive clones were checked for the presence of the $0.8 \mathrm{~kb}$ fragment by NdeI and XhoI restriction analysis.

Expression. BL21 (DE3) cells transformed with pET-DMP1 were grown on a rotating table (220 rpm) overnight at $37^{\circ} \mathrm{C}$ in $\mathrm{LB}$ medium with $50 \mu \mathrm{M}$ ampicilin. When the optical density at $600 \mathrm{~nm}$ of the bacterial broth reached $0.6-0.8$, the induction was realized with an addition of $1 \mathrm{mM}$ of 
isopropyl $\beta$-D-1-thiogalactopyranoside. After $3 \mathrm{~h}$, the cells were centrifuged at $5000 \mathrm{~g}$ for $10 \mathrm{~min}$ and the pellets were frozen at $-20^{\circ} \mathrm{C}$ until purification.

Purification. Pellets were resuspended in $5 \mathrm{~mL}$ of buffer A (PBS 1X, $50 \mathrm{mM}$ imidazole, complete inhibitor mix (Roche), lysozyme, DNAse) and lyzed by sonication three times. The bacterial extract was loaded on a $5 \mathrm{~mL}$ bed-volume HisTrap column using an Akta Purifier 10 (GEHealthcare). Buffer A was flowed through the column at $1 \mathrm{~mL} / \mathrm{min}$ until $\mathrm{A}_{280}$ of the flow through reached a stable value. A $60 \mathrm{~mL}$ linear gradient of 0-100\% Buffer B (PBS 1X, $500 \mathrm{mM}$ imidazole, Complete inhibitor mix (Roche), lysozyme, DNAse) in buffer A was applied and 1mL fractions were collected. Aliquots were analyzed by $10 \%$ SDS-PAGE and the gels stained with Coomassie blue to determine the quality of purified rpDMP1 (12 kDa, pI=4.14) (Figure S6).

\section{Sample Preparation}

Collagen extraction. A solution of type I collagen at $\sim 3 \mathrm{mg} / \mathrm{mL}$ in $0.5 \mathrm{M}$ acetic acid was prepared as previously described ${ }^{52}$ The collagen was extracted from rat tail tendons. After a washing step with phosphate-buffered saline (PBS), tendons were solubilized in $0.5 \mathrm{M}$ acetic acid and the solution was clarified by centrifugation $\left(21000 \mathrm{rpm}, 2 \mathrm{~h}, 11^{\circ} \mathrm{C}\right)$. The supernatant was selectively precipitated with $0.3 \mathrm{M}$ and $0.6 \mathrm{M}$ of $\mathrm{NaCl}$ by two centrifugations $\left(21000 \mathrm{rpm}, 3 \mathrm{~h}, 11^{\circ} \mathrm{C}\right.$ then 4400 $\mathrm{rpm}, 45 \mathrm{~min}, 11^{\circ} \mathrm{C}$ ), in order to remove proteins other than type I collagen and collagen respectively. The pellets were solubilized in $0.5 \mathrm{M}$ acetic acid and dialyzed against $0.1 \mathrm{M}$ acetic acid in order to remove salts from the solution. A final centrifugation was performed (21000 rpm, $4 \mathrm{~h}, 11^{\circ} \mathrm{C}$ ) and the concentration was adjusted to a final stock concentration of $\sim 3 \mathrm{mg} / \mathrm{ml}$. The final concentration of type I collagen solution was estimated by hydroxyproline titration. ${ }^{53}$ 
Synthesis of collagen/apatite matrices. The matrices were prepared according to a procedure that combines injection and reverse dialysis processes (patent WO2011151587A2). The mineralization conditions for collagen matrices (concentrations of components) are summarized in Table $\mathbf{1}$. Collagen samples were disk-shaped with a thickness of $\sim 1 \mathrm{~mm}$ and a diameter of $\sim 10 \mathrm{~mm}$. A soluble acidic collagen solution $(1 \mathrm{mg} / \mathrm{mL}, 0.5 \mathrm{M}$ acetic acid) supplemented by a $1 \mathrm{x}$ SBF solution mimicking the ionic compounds found in the human plasma was prepared by diluting the stock solution ( $3 \mathrm{mg} / \mathrm{ml}, 0.5 \mathrm{M}$ acetic acid) with a $1.5 \mathrm{x} \mathrm{SBF}$ acidic solution (0.5 M acetic acid). SBF was prepared as previously described. ${ }^{54}$ The concentrations of the salts precursors are summarized in Table S1. Two concentrations of rpDMP1 were added to this solution: $2.5 \mu \mathrm{g} / \mathrm{mL}$ (low) and 25 $\mu \mathrm{g} / \mathrm{mL}$ (high) to form the matrices referred as Coll/SBF-rpDMP1 and Coll/SBF-10rpDMP1, respectively. The rpDMP1 control matrix with the highest concentration of rpDMP1 and without mineral (Coll/10rpDMP1) was obtained by diluting the stock solution with acetic acid (0.5 M). Two matrices used as control were prepared: (i) without any organo-mineral additives (Coll) and (ii) with apatite ion precursors but without addition of any acidic polymer (Coll/SBF). The matrices supplemented by polyaspartate (Coll/SBF-polyAsp) were obtained in a similar way, by adding this acidic polymer $\left(5.75 \mu \mathrm{g} / \mathrm{mL}\right.$, Lanxess-Bayer, Baypure $\left.{ }^{\circledR} \mathrm{DS} 100,1200 \mathrm{~g} / \mathrm{mol}, \mathrm{pI}=2.98\right)$ to the acidic collagen solution. $40 \mathrm{mg} / \mathrm{mL}$ collagen matrices were also formed to mimic the osteoid tissue ${ }^{55}$ CollOsteoid/SBF/SBF. In this case, $25 \mu \mathrm{g} / \mathrm{mL}$ rpDMP1 was added to the acidic collagen solution forming the matrix referred as CollOsteoid/SBF-10rpDMP1/SBF. All these solutions were continually injected in a closed dialysis chamber for one week. The bottom of the chamber contained a dialysis membrane with a molecular weight cut off of $1 \mathrm{kDa}$. The reverse dialysis process $^{56}$ was set against polyethylene glycol (PEG, $35 \mathrm{kDa}$, Fluka) to control the final concentration of collagen. The PEG was dissolved in $0.5 \mathrm{M}$ acetic acid up to $\sim 300 \mathrm{mg} / \mathrm{mL}$ for all 
Coll matrices or $\sim 50 \mathrm{mg} / \mathrm{mL}$ for all CollOsteoid matrices. To form the mineralized matrices, the ionic precursors of SBF or CHA were dissolved in the PEG/acetic acid solution. After injection of the total amount of collagen, dialysis was continued for one week in order to obtain a homogeneous concentration in the samples and a good maturation of the peptides. The $\mathrm{pH}$ was then increased to a range of 9 to 10 by ammonia gas diffusion for 3 days to induce collagen fibrillogenesis, stabilize the liquid crystalline organization into dense fibrillar matrices and precipitate the mineral phase. These matrices were then removed from the dialysis chamber and washed several times in sterile double distilled water until complete neutralization. The final concentration of type I collagen in the different collagen matrices were assessed by hydroxyproline titration and found to be $\sim 250$ $\mathrm{mg} / \mathrm{mL}$ for all Coll matrices and $\sim 40 \mathrm{mg} / \mathrm{mL}$ for all CollOsteoid matrices. The different matrices were split into halves and the mineralization degree of one half was increased by a bath in $45 \mathrm{~mL}$ of $1.5 \mathrm{x} \mathrm{SBF}$ solution at $\mathrm{pH}=7.4$ under mild rotary stirring $(220 \mathrm{rpm})$ at $37^{\circ} \mathrm{C}$ during one week. ${ }^{8}$

\section{Mineral Characterization}

Histology. Bone samples were fixed in $4 \%$ paraformaldehyde and embedded in paraffin for sectioning. Ten $\mu$ m-thick serial sections perpendicular to the cell layer were dewaxed, rehydrated and stained specifically by von Kossa, thus identifying divalent ions. The slides were rinsed, dehydrated and mounted for observation with an optical microscope (Nikon E600 POL) or an epifluorescence microscope (AXIO 100 Zeiss).

Scanning electron microscopy (SEM) and energy-dispersive X-ray (EDX) spectroscopy. Each sample was fixed in $3.6 \%$ glutaraldehyde in a cacodylate/saccharose buffer solution $(0.05 \mathrm{M} / 0.6$ $\mathrm{M}$-pH 7.4). The samples were dehydrated through successive ethanol bath $(50 \%, 70 \%, 80 \%, 90 \%$ and $100 \%$ ) and a supercritical $\mathrm{CO}_{2}$ drying process was performed on a BAL-TEC 030. Then 
samples were sputter-coated with a gold layer of $10 \mathrm{~nm}$ and observed in a Hitachi S-3400N operating at $3 \mathrm{kV}$.

EDX microanalysis was used for the mapping of mineral deposits inside the matrices. The EDX instrument X-Max (Oxford Instruments) was coupled to a scanning electron microscope Hitachi S-3400N operating at $12 \mathrm{kV}$, and the Oxford Microanalysis Group XAN.70 software was used for this analysis.

Transmission electron microscopy (TEM). This protocol is similar to the protocol for the SEM. Then, samples were rinsed, dehydrated and embedded in Epon 812. For few samples (always mentioned in the text), an additional post-fixation was carried in $2 \%$ osmium tetroxyde in a cacodylate/saccharose buffer solution (0.4 M/0.6 M-pH 7.4) during $1 \mathrm{~h}$ at $4^{\circ} \mathrm{C}$ otherwise neither Osmium nor uranyl acetate (staining) were added to avoid artefacts on ultrathin sections. Sections $(\sim 80 \mathrm{~nm})$ were observed with a Tecnai spirit G2 operating at $120 \mathrm{kV}$.

Wide angle X-ray diffraction (WAXD, transmission mode). Matrices were inserted in X-ray cylindrical borosilicate capillary tubes. The tubes were wax-sealed to keep the samples hydrated, and placed directly in the vacuum chamber beam. X-ray diffraction experiments were performed with a S-MAX 3000 RIGAKU using a monochromatic $\mathrm{CuKa}$ radiation. The diameter of the cylindrical beam dimension of the specimen was $400 \mu \mathrm{m}$. The data were collected in the $3-60^{\circ}$

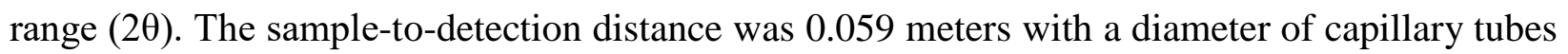
at $1 \mathrm{~mm}$ or 0.058 meters with a diameter of $2 \mathrm{~mm}$. The two-dimensional WAXD patterns were collected with imaging plates then scanned. The data were analysed using Image (LPS, U-psud) software. 
Zeta potential ( $\zeta$-potential) measurements. The matrices were washed before characterization precluding the involvement of free ions in the resulting global charge. Samples were crushed in liquid nitrogen and the resulting powders were dispersed in phosphate buffered saline (PBS) solution. Measurements were carried out using a Malvern Zetasizer Nano ZS90.

Thermogravimetric analysis (TGA). Samples were dried under laminar hood overnight to minimize the mass loss of loosely bounded water. The analysis was performed on a thermomicrobalance instrument (NETZSCH STA 409PC). The measurement was performed from room temperature to $1000^{\circ} \mathrm{C}$ in an oxidizing atmosphere (air) with a heating rate of $5^{\circ} \mathrm{C} / \mathrm{min}$.

Nuclear magnetic resonance. Solid-state Nuclear Magnetic Resonance (ssNMR) experiments were realized on hydrated samples. Magic angle spinning (MAS) spectra were acquired at a frequency of $8 \mathrm{kHz}$, with samples packed into $4 \mathrm{~mm}$ zirconia rotors. ${ }^{1} \mathrm{H}-{ }^{31} \mathrm{P}$ cross-polarization $(\mathrm{CP})$ experiments were performed on an Avance 300 Bruker spectrometer operating at frequencies of $300.13 \mathrm{MHz}\left({ }^{1} \mathrm{H}\right)$ and $121.50 \mathrm{MHz}\left({ }^{31} \mathrm{P}\right)$. The contact times (CT) were set at $10 \mathrm{~ms}$ and $1 \mathrm{~ms}$, and the recycle delay (RD) at $2 \mathrm{~s}$. A two-dimensional ${ }^{1} \mathrm{H}^{3}{ }^{31} \mathrm{P}$ heteronuclear correlation (HETCOR) was performed with the following parameters: $\mathrm{RD}=2 \mathrm{~s}, \mathrm{CT}=10 \mathrm{~ms}$ and $1 \mathrm{~ms}, 1280$ transients for each $128 \mathrm{t} 1$ increments. ${ }^{1} \mathrm{H}$ and ${ }^{31} \mathrm{P}$ chemical shifts were referenced $(\delta=0 \mathrm{ppm})$ to adamantane and to $85 \%$ w aqueous $\mathrm{H}_{3} \mathrm{PO}_{4}$, respectively. 


\section{RESULTS AND DISCUSSION}

Structural characterizations of rpDMP1-loaded mineralized collagen matrices. Experimental conditions and matrices composition (see Materials and Methods) are summarized in Table 1. It includes collagen matrices without additives used as control, namely Coll, Coll/SBF (Figure S1), Coll/CHA/SBF (Figure 1D, left) and Coll/SBF/SBF (Figure 1D, right) ${ }^{8}$. This means that after coprecipitation of collagen with either CHA ( 20 times more concentrated in apatite ion precursors see Table S1) or SBF, these two last matrices were then immersed in SBF to mimic further steps of mineral growth. With additives (rpDMP1, polyAsp), fibril precipitation was only performed in SBF $\left(\left[\mathrm{Ca}^{2+}\right]=\left[\mathrm{Ca}^{2+}\right] \mathrm{ECF}\right){ }^{57}$ to set physiological-like conditions. Two concentrations of rpDMP1 were used here, for which we will refer to low $(2.5 \mu \mathrm{g} / \mathrm{mL}, 1 \mathrm{rpDMP} 1)$ and high $(25 \mu \mathrm{g} / \mathrm{mL}$, 10rpDMP1). For a better reading, data for 10rpDMP1 are displayed in the main text only when differences in mineral formation are observed between the two concentrations. Additional data for 10rpDMP1 are shown in Figure S2. 
Table 1. Mineralization conditions for collagen matrices. Ionic composition of SBF and CHA solutions are detailed in Table $\mathbf{S 1 .}$

\begin{tabular}{lcccc}
\hline Sample designation & $\begin{array}{c}\text { End collagen } \\
\text { concentration } \\
(\mathrm{mg} / \mathrm{mL})\end{array}$ & $\begin{array}{c}\text { Acidic } \\
\text { polymer } \\
(\mu \mathrm{g} / \mathrm{mL})\end{array}$ & $\begin{array}{c}\text { Hydroxyapatite } \\
\text { ion precursors } \\
\text { in dialysis } \\
\text { solution (acetic } \\
\text { acid })\end{array}$ & $\begin{array}{c}\text { Additional } \\
\text { SBF bath }\end{array}$ \\
& 250 & - & - & - \\
\hline Coll & 250 & - & SBF & - \\
Coll/SBF & 250 & - & SBF & + \\
Coll/SBF/SBF & 250 & - & CHA & + \\
Coll/CHA/SBF & 250 & 2.5 & SBF & - \\
Coll/SBF(rpDMP1) & 250 & 2.5 & SBF & + \\
Coll/SBF(rpDMP1)/SBF & 250 & 25 & - & - \\
Coll/10rpDMP1 & 250 & 25 & SBF & - \\
Coll/SBF(10rpDMP1) & 250 & 25 & SBF & + \\
Coll/SBF(10rpDMP1)/SBF & 250 & 5.75 & SBF & - \\
Coll/SBF(polyAsp) & 250 & 5.75 & SBF & + \\
Coll/SBF(polyAsp)/SBF & 40 & - & SBF & + \\
CollOsteoid/SBF/SBF & & 25 & SBF & + \\
CollOsteoid/SBF(10rpDMP1)/SBF & 40 & & & + \\
\hline & & & & + \\
\hline
\end{tabular}


We first investigated the spreading of mineral within collagen matrices before and after immersion in SBF for both rpDMP1 concentrations. For this purpose, we used von Kossa staining on histological sections as it allows observations at large scale. Interestingly, staining is hardly observed without SBF extra-bath (Coll/SBF(1rpDMP1), Figure 2A) whereas a strong staining is observed for both matrices at the superficial layer $(\sim 50 \mu \mathrm{m}$ thick $)$ after immersion (Coll/SBF(1rpDMP1)/SBF, Figure 2B). Because von Kossa staining may interfere with any divalent ions ${ }^{58}$, further characterizations were performed to confirm the presence of mineral.

To identify the distribution of the mineral at lower scale, investigations were performed at the surface and inside fractured disk-shaped matrices (Figure 2C-G) using SEM coupled with EDX microanalysis (Figure 2H). Observations inside the matrix reveal that the entrapment of rpDMP1 does not disturb the self-assembly of collagen fibrils since twisted plywood structure form over large distances (Figure 2C-D versus Figure S1, Coll/SBF). After immersion in SBF (Coll/SBF(1rpDMP1)/SBF), the surface roughness is more pronounced by the deposition of particles on the closely packed oriented fibrils (Figure 2D versus $2 \mathbf{E}$, arrow). On the surface of the matrices, spherulites usually consisting of aggregates crystals ${ }^{59}$ are observed and, interestingly, they appear to be smaller in the presence of the protein $(\sim 0.5 \mu \mathrm{m}$ versus $\sim 4 \mu \mathrm{m}$ in Coll/SBF/SBF, yellow dashed circles in Figure 2F and Figure 2G). In addition, they appear less abundant since they do not cover the whole surface. EDX analysis shows that the spherulites are mainly composed of calcium and phosphorus atoms with an average $\mathrm{Ca} / \mathrm{P}$ ratio of about $1.66-1.71$, suggesting the formation of apatite in the presence of rpDMP1 (Figure 2H) ${ }^{60}$ 

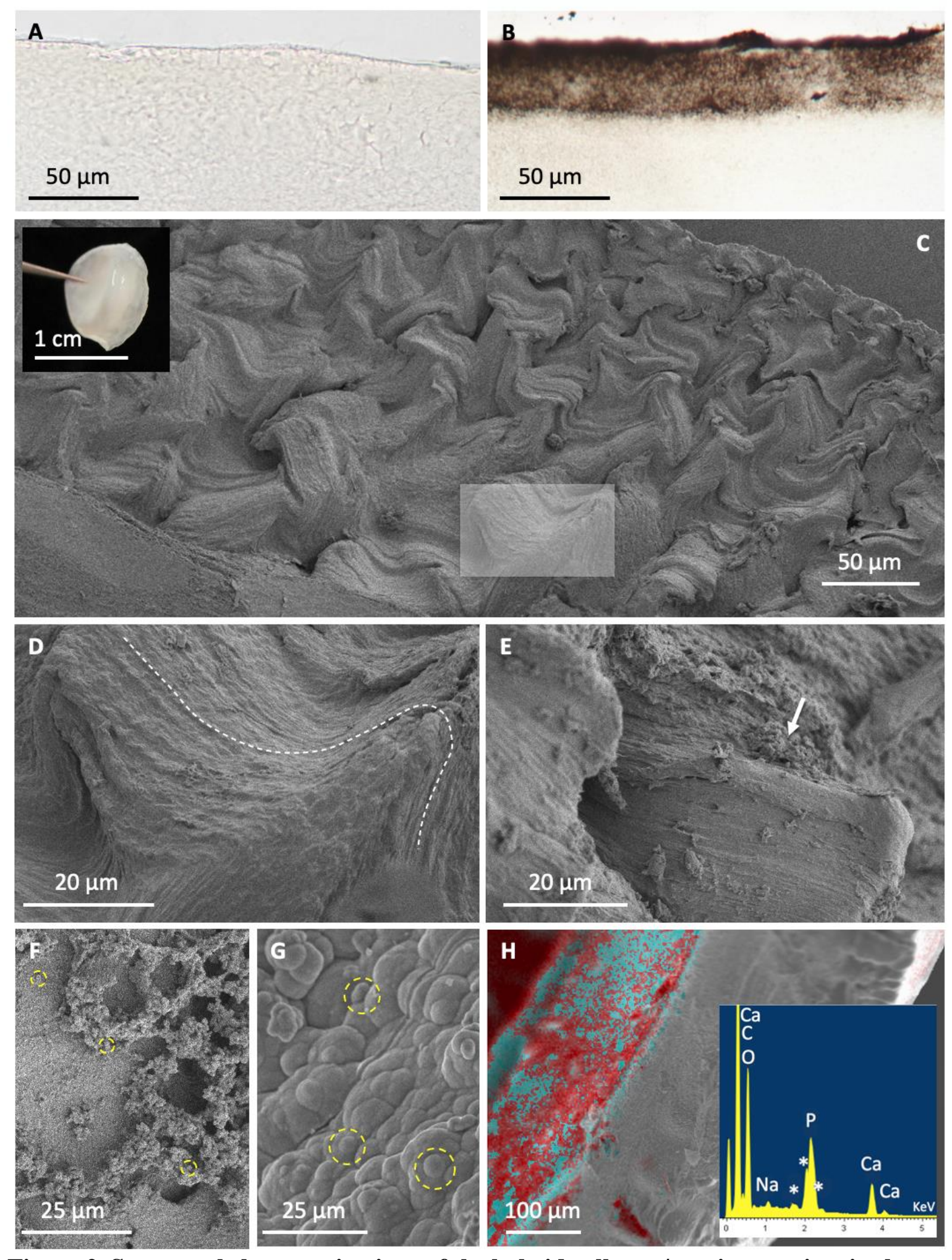

Figure 2. Structural characterizations of the hybrid collagen/apatite matrices in the presence of rpDMP1 containing the highly conserved motif. Histological sections of Coll/SBF(1rpDMP1) (A) and Coll/SBF(1rpDMP1)/SBF (B) stained with von Kossa. SEM observations of the dense collagen matrix $(250 \mathrm{mg} / \mathrm{mL})$ at low rpDMP1 content (C-F). 
Examination of the fractured interior of the disk-shaped matrix ( $\mathbf{C}$, inset) before SBF bath (Coll/SBF(1rpDMP1) (C, D; rectangle in $\mathbf{C}$ indicates the enlarged section that is shown in D). Examination after SBF bath (Coll/SBF(1rpDMP1)/SBF): interior $(\mathbf{E})$ and surface $(\mathbf{F})$. In $(\mathbf{E})$, the roughness appears to increase after SBF (arrow). (G) Surface of the collagen matrix precipitated without rpDMP1 (Coll/SBF/SBF). The size and the amount of spherulitic crystals (yellow dashed circles) at the surface of the matrices decrease with rpDMP1. (H) Analysis of Coll/SBF(1rpDMP1)/SBF by EDX coupled with SEM; calcium ions are in red and phosphorus ions in blue (SEM gold coating*). 
Confinement effect on apatite/rpDMP1 distribution. Then, TEM investigations were performed on thin sections of Coll/SBF(1rpDMP1) and Coll/SBF(10rpDMP1) to access higher magnifications. TEM sections were not stained to avoid the presence of staining deposits that are difficult to distinguish from $\mathrm{CaP}$ crystals. ${ }^{8}$ Observations evidence the presence of nanometric electron-dense ('dot-like’) precipitates $(\sim 30 \mathrm{~nm})$ with low and high rpDMP1 concentrations (red arrows in Figure 3A and Figure 3B, respectively) within the dense collagen network at this scale. The striated pattern $(67 \mathrm{~nm})$ is observed locally (Figure 3A, inset) indicating that some mineral localise inside the gap regions. ${ }^{8,61}$ Interestingly, additional aggregates of nanoprecipitates are observed for high rpDMP1 content (Figure 3B, yellow dashed circle).

To help identify the nature of the "dot-like" precipitates, a control matrix was prepared without apatite ion precursors (Coll/10rpDMP1) (Figure 3C). Likewise, "dot-like" particles are observed (white arrows) confirming that the nanoprecipitates are also composed of the protein, in agreement with previous observations. ${ }^{14}$ Although it is difficult to conclude due to the low contrast of organic components in TEM, the precipitates appear less abundant and not distributed along the fibrils (Figure 3C versus Figure 3A-B). Nevertheless, spherulites are observed without rpDMP1 in SBF (Coll/SBF/SBF in Figure 1D and Coll/SBF ${ }^{\mathbf{8}}$ ) indicating that rpDMP1 may interfere with some ions to localize specifically inside the gap zone.

After SBF bath, few platelets with axial alignment (blue arrow in Figure 3D) are observed for both rpDMP1 concentrations together with spherulitic particles at the surface and within the most superficial layer of the matrix (dashed yellow circles in Figure 3E and Figure 3F). Noticeably, they appear smaller in size $(\sim 300 \mathrm{~nm}$ versus $\sim 2 \mu \mathrm{m})$ than those found without rpDMP1 (Figure 1D, right) but remain crystalline according to the contrast observed in the dark-field TEM image (Figure 3E'). Further observations at the surface of Coll/SBF(10rpDMP1)/SBF allow the 
visualization of both the resin and individual fibril due to a lower density of collagen locally. A comparison between mineralized collagen fibrils without or with staining (Figure $\mathbf{F}$ and Figure F', respectively) confirms the precipitation of fibrils with the cross-striated pattern. Observations of unmineralized collagen matrix without staining (Coll, Figure $\mathbf{H})$ where the resin is darker than collagen confirm that the contrast in mineralized samples comes from the spreading of mineral (ions or precipitates) over the collagen fibrils. Note that we cannot conclude on the involvement of DMP1 in mediating the size of fibrils, ${ }^{29}$ since the average diameter of collagen fibrils appears unmodified ( 100 $\mathrm{nm})$ regardless the rpDMP1 concentration.

Going further, TGA investigations were performed to better characterize the effect of rpDMP1 concentration on apatite formation (Figure S3). Considering the standard deviation recorded for the matrices $\left( \pm 5^{\circ} \mathrm{C}\right)$, the difference in mineralization degree should be considered as a trend here. After SBF bath, the mineral content increases for low rpDM1 concentration (from $\sim 3.5 \%$ to $\sim 18 \%$ ) whereas it does not change significantly at high content of rpDMP1 (from $\sim 12.5 \%$ to $\sim 15 \%$ ). Since both matrices exhibit spherulites on the surface after SBF bath (Figure $2 \mathbf{F}$ and Figure S2C), it indicates that the main mineral content is localized inside the matrix in the form of nanoprecipitates.

In addition, $\zeta$-potential was investigated to help understand the interactions between collagen, rpDMP1 and the mineral. Before SBF bath, the global surface charge tends to be neutral in the presence of rpDMP1 whatever the concentration of the protein $(-0.79( \pm 0.66) \mathrm{mV}$ and $0.22( \pm 0.78)$ $\mathrm{mV}$ for low and high rpDMP1 concentration, respectively). Indeed, the Coll/SBF matrix exhibits a negative $\zeta$-potential $\left(-4.3( \pm 2.5) \mathrm{mV} .{ }^{8}\right.$ This result agrees with a partial coating of collagen by the selected DMP1 domain, which includes the two collagen binding sites ${ }^{29}$ and the highly conserved acidic peptide. ${ }^{37}$ Indeed, it is reported that DMP1 binds to the N-telopeptide region in collagen..$^{29,45}$ 
After immersion in SBF, Coll/SBF(1rpDMP1)/SBF exhibits a more negative $\zeta$-potential (-9.77 $( \pm 0.48) \mathrm{mV}))$ while it is slightly unchanged for Coll/SBF(10rpDMP1)/SBF $(-1.79( \pm 0.33) \mathrm{mV})$. The $\zeta$-potential of hydroxyapatite being negative between $\mathrm{pH} 5$ and 8 ( -5 to $-37 \mathrm{mV}$ respectively), ${ }^{62}$ this is in agreement with the TGA analysis. 

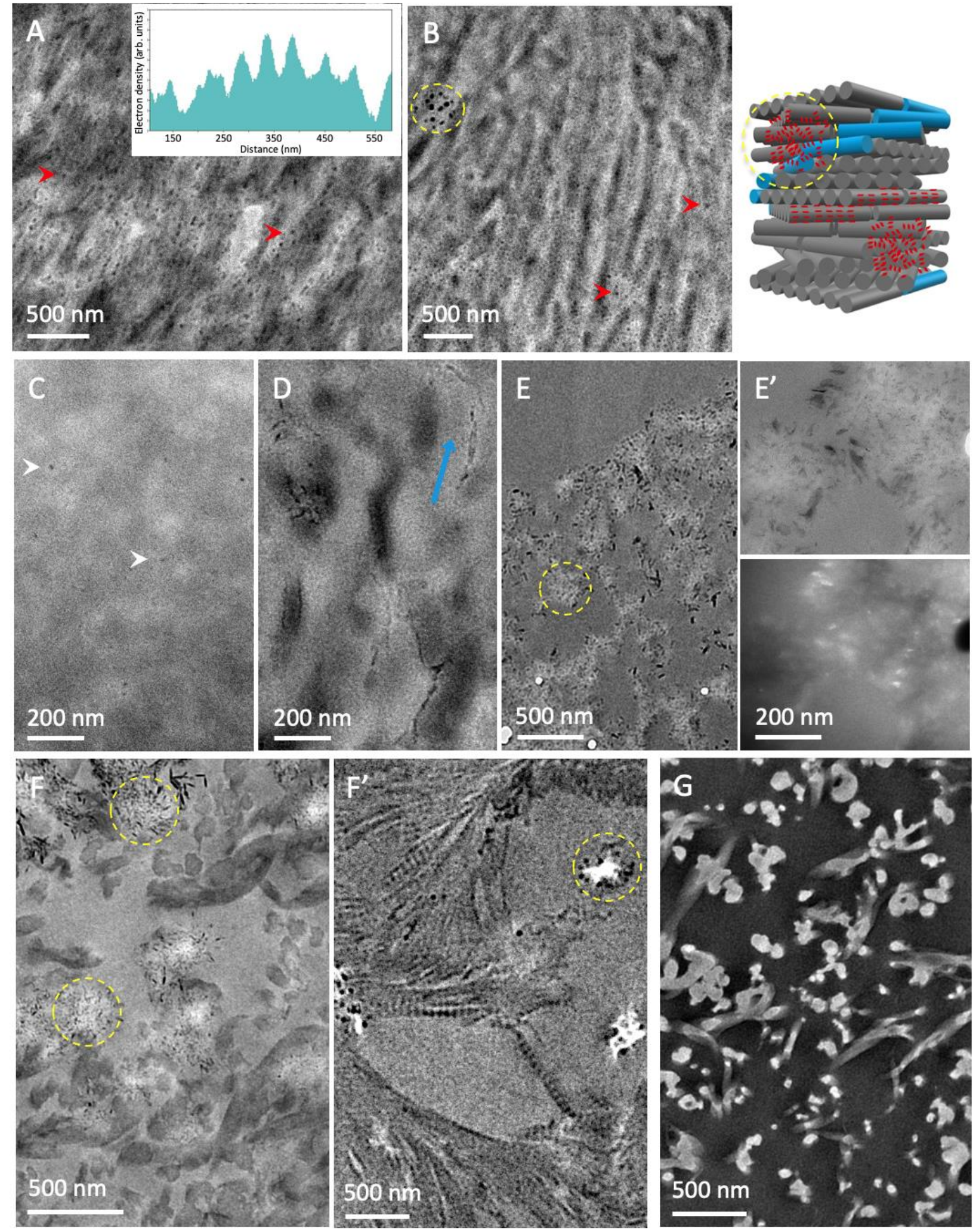

Figure 3. Investigations by TEM of calcium phosphate precipitation in rpDMP1 containing mature bone-like matrix. Observations of unstained ultrathin sections of (A) 
Coll/SBF(1rpDMP1) and (B) Coll/SBF(10rpDMP1) before the SBF bath. Both matrices present nanometric electron-dense precipitates (red arrows) along and/or within the collagen fibrils with periodicity highlighted by the intensity profile. In addition, aggregates of the dot-like" precipitates are seen in Coll/SBF(10rpDMP1); the scheme illustrates the corresponding distribution of dot-like precipitates (red) related to the organization of collagen fibrils. They are found along the fibrils or as aggregates (yellow dashed circle); (C) A control matrix prepared with the high concentration of rpDMP1 $(25 \mu \mathrm{g} / \mathrm{mL})$ and without ionic apatite precursors (Coll/10rpDMP1) shows that collagen fibrils are hardly observed in contrast to the precipitated proteins (yellow arrows). After immersion in SBF, (D) axial alignment of platelets are observed inside the matrix (E) Observations within the most superficial layer of the matrix show the presence of spherulitic crystals ( $\left.\mathbf{E}^{\prime}\right)$ according to bright/dark field images. Observations at the surface of Coll/SBF(10rpDMP1)/SBF (F) without and $\left(\mathbf{F}^{\prime}\right)$ with staining where the dashed yellow circles highlight the presence of spherulite; Observations at the surface of (G) Coll without staining. 
To go deeper in the understanding of how the suprafibrillar confinement affects the spreading of rpDMP1 over collagen, the peptide was entrapped in a scaffold mimicking the fibrillar arrangement of osteoid tissue (Figure 4A and Figure 4B). As mentioned above, this means that (i) the fibrils network is not as dense as the previous mature-bone model with larger interfibrillar spaces which are above the micron size (macroporous gel), and (ii) the collagen fibrils are not organized (no plywood geometry). Note that spherulitic crystals form in the control matrix without peptide (CollOsteoid/SBF/SBF) as shown by SEM (Figure 4C) and TEM (Figure 4D), which is in agreement with previous observations on a matrix with a collagen gradient concentration. ${ }^{8}$

Interestingly, "dot-like" precipitates are also observed but they do not localize inside the fibrils (Figure 4A). Although most of the investigations have focused on electrostatic interactions to explain the intrafibrillar infiltration of both mineral and proteins in collagen, this difference in apatite crystals distribution in osteoid- and mature bone-like matrices evidences that the suprafibrillar confinement provided by the collagen assembly in bone tissue (i.e. cholesteric geometry) plays a key role on this phenomenon. Thus it may explain the need of other proteins to infiltrate collagen in models lacking biomimetic interfibrillar spaces $(<1.7 \mathrm{~nm}) .{ }^{45}$ The fact that collagen here is continuously in contact with ions (even before mineralization) as occurring in bone strengthens the need of a balance between osmotic equilibrium and electroneutrality for intrafibrillar mineralization. ${ }^{63}$ In addition, the use of biomimetic collagen interfibrillar spaces (in both osteoid- and mature-like matrices) contradicts that rpDMP1 favors the templating of crystal growth. ${ }^{14}$ Conversely, according to $(i)$ TEM and SEM investigations where it is observed that the size of spherulites consist of either "dot-like" aggregate or "mature" apatite platelets with (Figure 2F, Figure 3B and Figure 4 A-B) or without rpDMP1 (Figure 2G and Figure 4 C-D) respectively, (ii) the mineral amount found by TGA and (iii) the resulting surface charge probed by zeta 
potential, we confirm its role as growth inhibitor. ${ }^{33}$ This effect may be related to the confinement which promotes the protein folding by destabilizing the unfolded state ${ }^{64,65}$ and thus further specific interactions between rpDMP1 and apatite nuclei; the structural characteristics of growing apatite being driven by the involvement of ionic substitutions (specifically from carbonate ions). ${ }^{66}$ 

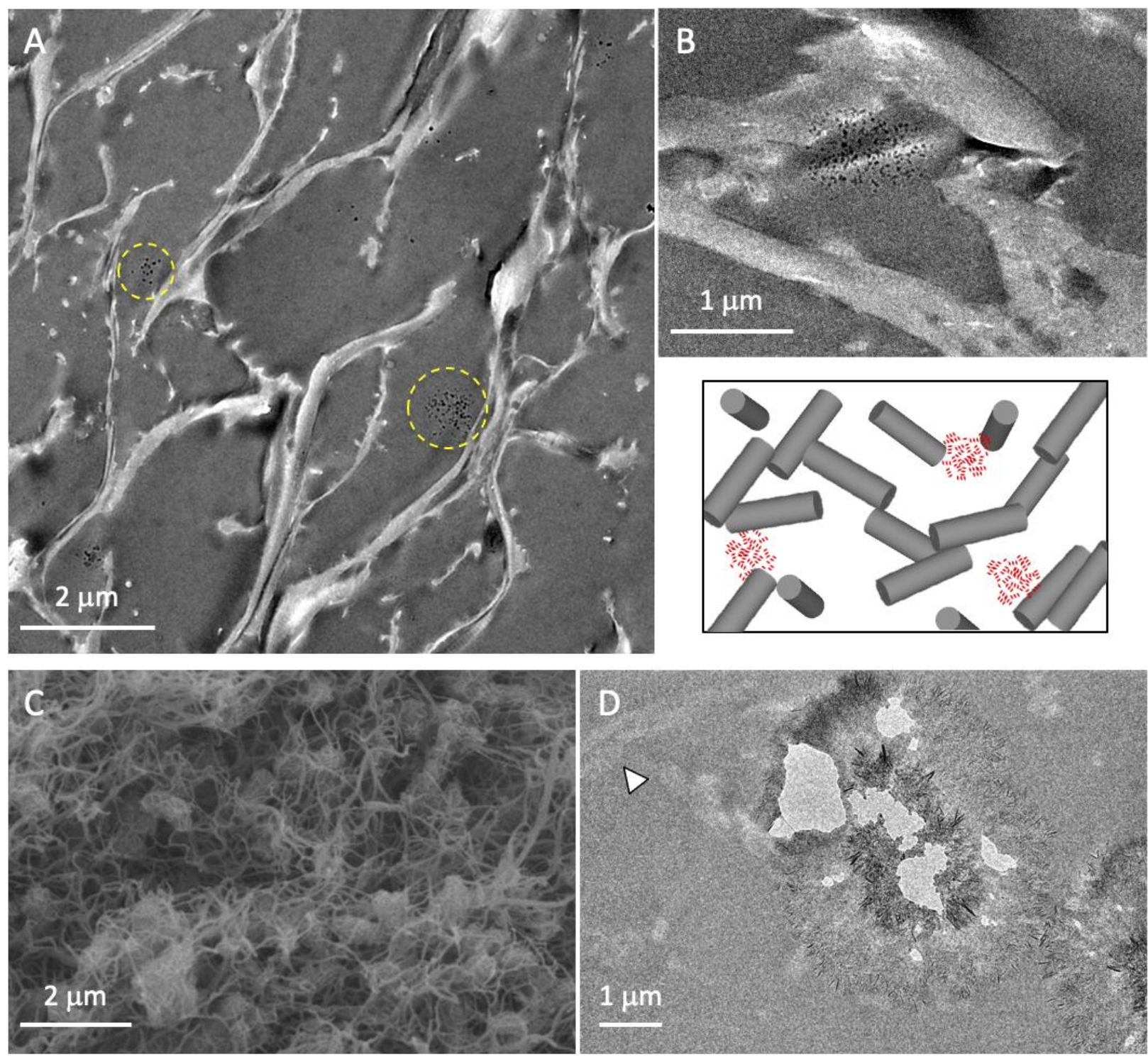

Figure 4. Investigations of calcium phosphate precipitation in rpDMP1 containing osteoidlike matrix. TEM observations of unstained ultrathin sections of CollOsteoid/SBF(10rpDMP1)/SBF (A) at low magnification where "dot-like" precipitates aggregate locally (yellow dashed circle). They are clearly seen $(\mathbf{B})$ at higher magnification. Below, the corresponding relationship between mineral and collagen is represented in the scheme. Scanning (C) and Transmission (D) EM micrographs of CollOsteoid/SBF/SBF. The absence of staining makes difficult the observation of cross-striated fibrils usually seen in a longitudinal cut (white arrow). 
Towards evidence of the specific activity of rpDMP1 under confinement. When polyAsp is supplemented to collagen, it is difficult to observe a difference in mineral spreading over the collagen matrix before immersion in SBF (Coll/SBF(polyAsp), Figure 5A) as compared to rpDMP1. Here also, a lower concentration of polyAsp $(5.75 \mu \mathrm{g} / \mathrm{mL})$ was used than that in the literature (usually between 10 and $100 \mu \mathrm{g} / \mathrm{mL}$ ) (i) to reach at least 2 magnitude order lower amounts of negative charge, and (ii) to reproduce a more "realistic" collagen to NCPs ratio since such high polyAsp concentration can be used for one single fibril. ${ }^{3}$ Note that our samples were not lyophilized before characterization as it is commonly performed with this polymer in the literature. ${ }^{67}$ This is of importance since the resulting phase and degree of mineralization are here related to a hydrated biomimetic process. Difference between polyAsp and rpDMP1 in apatite mineralization becomes clearer after the SBF bath (Coll/SBF(polyAsp)/SBF, Figure 5B-C). TEM observations reveal large domains where the mineral platelets coalign with the collagen fibrils (Figure 5B) as seen in mature bone (Figure 1C) strengthening the affinity of polyAsp for gap regions in line with previous conclusions in the literature. ${ }^{44,45,68}$ However, in contrast to rpDMP1 results, non-biomimetic spherulitic crystals are also observed in the matrix (Figure 5C and Figure 5D) strengthening that only small molecules such as osteocalcin can penetrate alone the intrafibrillar space ${ }^{69}$.

These observations evidence the specificity of biological rpDMP1 versus synthetic polyAsp amino-acids sequences in mediating apatite mineralization and also suggest that, in addition to its role as growth inhibitor, it may prevent homogeneous nucleation ${ }^{33}$. Finally, the rpDMP1 sequence being not phosphorylated, this result tends to strengthen that the organic phosphate concern may be attributed to polyadenosine di-phosphate ribose. ${ }^{70}$ 

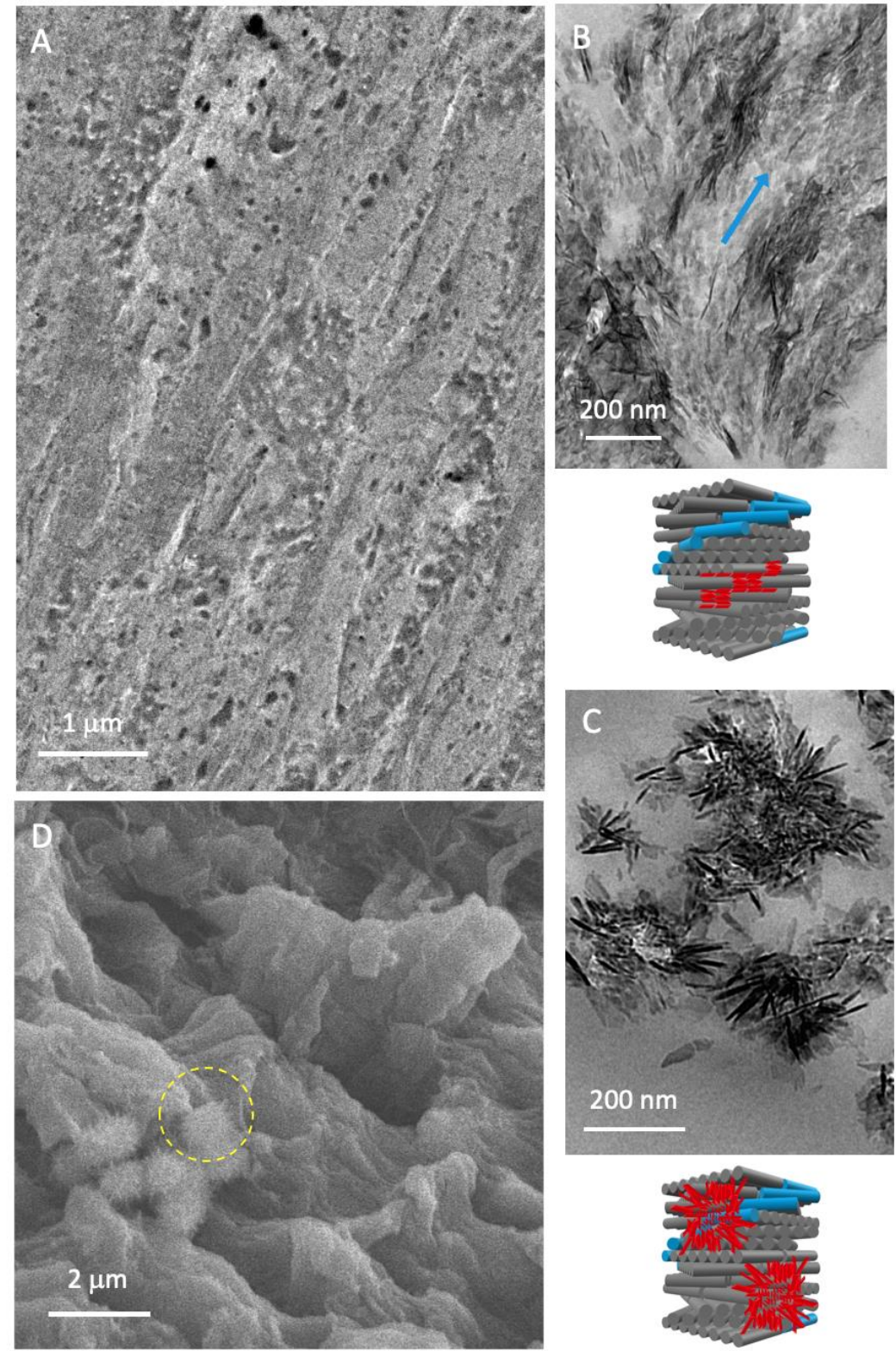

Figure 5. Calcium phosphate precipitation investigated by EM in the presence of polyAsp containing mature bone-like matrix. Observations by TEM of unstained ultrathin sections of, matrices before and after SBF immersion, (A) Coll/SBF(polyAsp) and (B-C) Coll/SBF(polyAsp)/SBF, respectively. The corresponding schematic representation of the apatite crystal (red)/collagen fibril (grey) relationship in a 3D perspective is shown. The lack of staining in (A) indicates that there is an homogeneous spreading of SBF ions over the collagen. After immersion in SBF (B-C), HA platelets are observed in the matrix; they either (B) co-align with the long axis of the fibril (blue arrow) or (C) form spherulites as schematically presented respectively below the (B) and (C) TEM micrographs; (D) SEM micrograph of Coll/SBF(polyAsp)/SBF showing that spherulites (yellow dashed circle) are also observed inside the matrix. 
Structural features of rpDMP1-mediated mineral under confinement. WAXD studies were performed to better characterize the mineral phase and collagen network. One-dimensional radial average of the WAXD patterns are shown in Figure 6A. Without SBF extra-bath, the signal from collagen fibrils is strong revealing a low degree of mineralization (dashed green and blue lines). The characteristic HA diffraction peaks, i.e. (002) and the merged (211), (300), (202) reflections, are observed more clearly after the SBF bath (full green and blue lines), especially for Coll/SBF(1rpDMP1)/SBF confirming an increase in mineral content. In addition, the lateral distance between collagen molecules decreases from $1.5 \mathrm{~nm}$ to $1.1 \mathrm{~nm}$ in the matrices loaded with rpDMP1 (with or without SBF bath) in comparison to the pure collagen matrix (full purple line) as observed by the peak shift towards high angles (vertical grey dashed line). This distance is shorter than that reported for mineralized dense collagen scaffold without protein ${ }^{7}$ but agrees with densely packed microfibrils ${ }^{[71]}$ and fibrillar collagen in a dry state. ${ }^{72}$ Since the sample is studied in its native hydrated form, this decrease in the intermolecular distance in addition to the contrast observed in fibrils by TEM confirm that rpDMP1 localizes inside the gap zones. The peptide may co-localize with the mineral as shown for polyelectrolytes. ${ }^{63}$ Besides confinement, SBF ions are needed for the protein to localize in intrafibrillar spaces, specially calcium ions considering the model of a periodic assembly of DMP1 into a $\beta$-sheet template with high calcium-binding capacity. ${ }^{14}$ Then the Ca-binding protein can interact with a significant fraction of the $\mathrm{Pi}$, that is possibly covalently bond to the collagen. ${ }^{73}$ At a critical concentration of $\mathrm{Ca}^{2+}$, the apatite nucleation which strongly depends on the degree of confinement ${ }^{74}$ occurs inside collagen. However, since apatite forms without organic additives under collagen confinement, ${ }^{8}$ it shows that rpDMP1 increases the local ions concentration but does not initiate the nucleation here.

To investigate the presence of calcium-phosphate minerals described as transient phases in 
bone formation ${ }^{51,75,76}$ and better understand the local phosphate environment in collagencontaining rpDMP1, ${ }^{31} \mathrm{P}$ solid state nuclear magnetic resonance (NMR) experiments were performed (Figure 6B-E). The ${ }^{31} \mathrm{P}$ CP MAS spectrum of Coll/SBF(1rpDMP1) displays a single ${ }^{31} \mathrm{P}$ resonance centred at $2.8 \mathrm{ppm}$, typical of apatite (Figure $6 \mathbf{B}$ blue). Interestingly, the $2 \mathrm{D}{ }^{1} \mathrm{H}^{31} \mathrm{P}$ HETCOR spectrum of Coll/SBF(10rpDMP1) does not show the correlation resonance characteristic from $\mathrm{HPO}_{4}{ }^{2-}$ (Figure 6C) excluding the presence of a hydrated disordered surface layer ${ }^{66,77}$ In addition, the linewidth of the ${ }^{31} \mathrm{P}$ resonance $(\mathrm{LW}=1 \mathrm{ppm})$ is thinner than matrices prepared without rpDMP1 (Coll/SBF, LW = 2 ppm) (Figure S4). Both the thinner resonance and the absence/low amount of $\mathrm{HPO}_{4}{ }^{2-}$ surface species demonstrate that the mineral "dot-like" precipitates of the matrices are highly crystalline and that rpDMP1 drives the higher crystallinity of apatite. This result is in agreement with previous works proposing that DMP1 impacts on the initial stages of apatite formation providing a structural local order. ${ }^{14}$ Interestingly, DMP1 is found more abundant in the boundary between the dentin and enamel where apatite is well crystallized. ${ }^{30}$ Finally, it is interesting to note that such "dots-like crystals" reminds that found at the very early stages of normal in vivo calcification. ${ }^{1}$ After SBF bath, the ${ }^{31} \mathrm{P}$ line width in CP MAS spectrum increases (Figure 6B, red) reaching the value found for bone apatite $(4.1 \mathrm{ppm}){ }^{78}$ The fact that the 2D ${ }^{1} \mathrm{H}^{31} \mathrm{P}$ HETCOR spectrum of Coll/SBF(1 rpDMP1)/SBF (CT = $10 \mathrm{~ms}$ ) (Figure 6D) displays the two typical resonances of bone mineral, i.e. $\delta\left({ }^{31} \mathrm{P}\right)=2.8 \mathrm{ppm}$ and $3.2 \mathrm{ppm}$, shows that the apatite spherulites observed at the surface of the matrices by microscopy (Figure 2F) dominate here the spectroscopic signature.

At higher rpDMP1 content, 1D ${ }^{31} \mathrm{P}$ CP-MAS spectra (Figure 6E) display two shoulders (centred at 1.5 and $-1 \mathrm{ppm}$ ) in addition to the apatite resonance at $2.8 \mathrm{ppm}$ before and after SBF. These resonances correspond to the $\mathrm{HPO}_{4}{ }^{2-}$ ions from the OCP phase. Noticeably, the presence of 
a relatively low content of rpDMP1 leads to the physiological single apatitic phase whereas high "non-physiological" concentration of protein stabilizes an additional CaP phase like OCP. Such high concentrations are classically used in the literature questioning the role of DMP1 in stabilizing

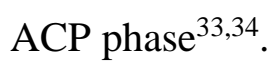

HRTEM observations performed on ultrathin sections of Coll/SBF(1rpDMP1)/SBF (Figure 6F and Figure S5) confirm the highly crystalline nature of the "dot-like" precipitates. Spaced thin layers that are mostly concentric, i.e. onion-like morphology that appear to be composed of crystalline nano-domains $(\sim 1 \mathrm{~nm})$ (some are depicted in areas 1 and 2$)$ are observed. Schematic representations of two selected areas (1 and 2) show the orientation of possible crystal planes (f1 and f2). Some crystalline nano-domains appear to align along the same direction (in red). Their morphology is difficult to identify; they are presented here as parallelogram. In (f3) and (f4), Fast-Fourrier Tranform (FFT) (f3a and f4a) and inverse FFT (f3b and f4b) performed on the ( 3 and 4 ) selected areas confirm the presence of crystalline nano-domains. The crystal planes were indexed by comparing the measured d spacings using the FFT profile along one direction with calculated values of hydroxyapatite ( $\mathrm{f} 3 \mathrm{c}$ and $\mathrm{f} 4 \mathrm{c}$ ). Two lattice spacings were measured as 0.31 and $0.34 \mathrm{~nm}$ corresponding to the known (210) and (002) crystal planes of apatite (Figure $6 \mathbf{F}$ and Figure S5, respectively). Among the twenty analyzed planes, $80 \%$ correspond to the (210) and the remaining $20 \%$ to the (002).

The possible consequence of a crystalline apatite nano-domain versus an ACP phase can prevent the formation of pathological calcifications. Indeed, ACP as first solid phase of calcium phosphate formed in bone would delay apatite formation allowing the precipitation of other transient phases. This hypothesis is in agreement with the fact that the mineralization process of bone is described to occur rapidly as soon as collagen molecules self-assemble into collagen fibrils 
in the extracellular space. ${ }^{79}$ In fact, according to our knowledge, there is no report on bone pathologies related to the presence of one of the transient apatite phases although it is extensively described in synthetic models lacking interfibrillar confinement in vitro as discussed above. 

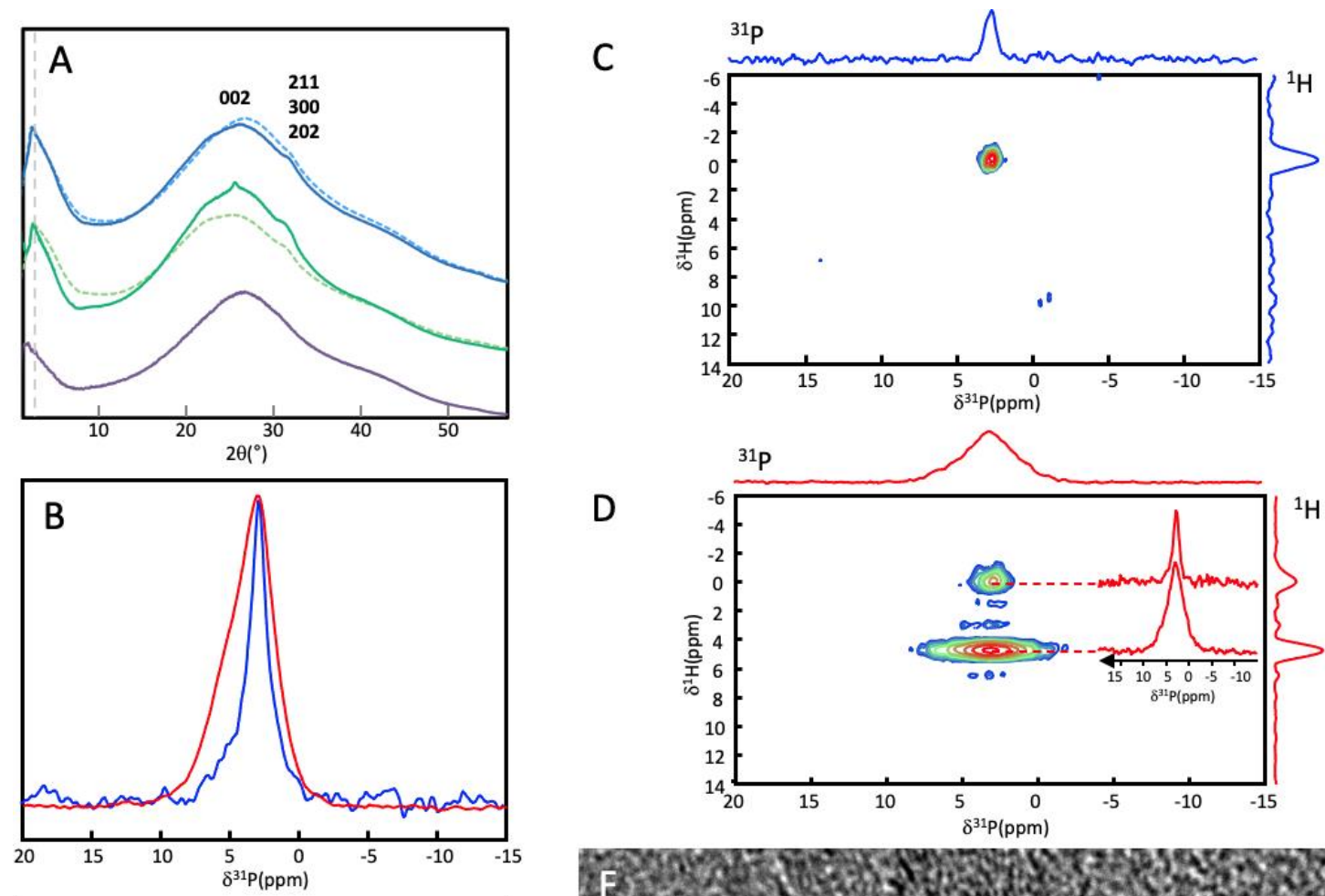

D
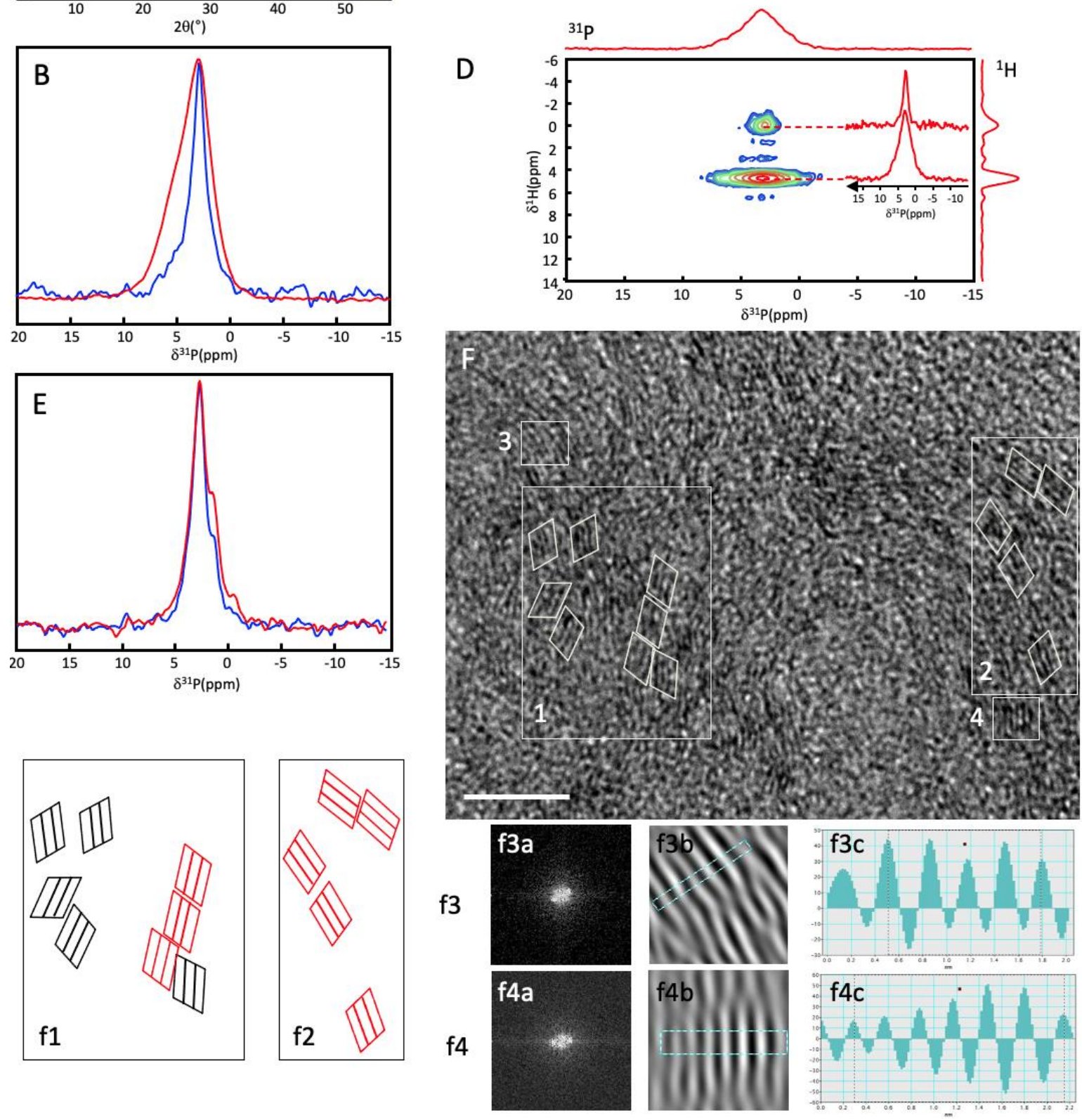

Figure 6. Characterization of the mineral phase. (A) One-dimensional radial average of the WAXD patterns of matrices at $2.5 \mu \mathrm{g} / \mathrm{mL}$, without (Coll/SBF(1rpDMP1), dashed green) and with (Coll/SBF(1rpDMP1)/SBF, plain green) immersion in SBF; at $25 \mu \mathrm{g} / \mathrm{mL}$, without 
(Coll/SBF(10rpDMP1), dashed blue) and with (Coll/SBF(10rpDMP1)/SBF, full blue) immersion in SBF, and a collagen matrix as control (purple), the vertical grey dashed line points out the shift of the reflection which corresponds to the lateral distance between collagen molecules; (B) $1 \mathrm{D}^{31} \mathrm{P}$ CP MAS spectra $(\mathrm{CT}=10 \mathrm{~ms})$ of the hybrid matrices Coll/SBF(1rpDMP1) (blue) and Coll/SBF(1rpDMP1)/SBF (red). (C) $2 \mathrm{D}{ }^{1} \mathrm{H}^{3}{ }^{31} \mathrm{P}$ HETCOR spectrum (CT $=10 \mathrm{~ms}$ ) of Coll/SBF(1rpDMP1) with extracted ${ }^{31} \mathrm{P}$ slices at $\delta\left({ }^{1} \mathrm{H}\right)=0$ and $4.9 \mathrm{ppm}$. (D) $2 \mathrm{D}{ }^{1} \mathrm{H}^{-31} \mathrm{P}$ HETCOR spectrum $(\mathrm{CT}=10 \mathrm{~ms})$ of Coll/SBF $(1 \mathrm{rpDMP} 1) / \mathrm{SBF}$. (E) $1 \mathrm{D}^{31} \mathrm{P}$ CP MAS spectra $(\mathrm{CT}=10 \mathrm{~ms})$ of the hybrid matrices Coll/SBF(10rpDMP1) (blue) and Coll/SBF(10rpDMP1)/SBF (red). (F) TEM micrograph of Coll/SBF(1 $1 \mathrm{rpDMP} 1) / \mathrm{SBF}$ (scale bar $=5 \mathrm{~nm}$ ) showing crystalline hydroxyapatite nano-domains. (f1) and (f2) are schematic representations of the selected areas 1 and 2 showing the orientation of the hydroxyapatite (210) planes; some crystalline nano-domains appear to align along the same direction (red). (f3) and (f4) Fast-Fourrier Tranform (FFT) (f3a and $\mathrm{f} 4 \mathrm{a}$ ) and inverse FFT ( $\mathrm{f} 3 \mathrm{~b}$ and f4b) performed on the selected areas 3 and 4 confirming the presence of crystalline nano-domains. D spacing's are measured using the inverse FFT profile along one direction ( $\mathrm{f} 3 \mathrm{c}$ and $\mathrm{f} 4 \mathrm{c}$ ). 


\section{CONCLUSION}

The bone ECM is a dynamic (in terms of structure, remodelling and ECF) and complex environment where confinement effect occurs that is not only critical for the cells behaviour ${ }^{80}$ but also for the proteins and even the solvent (water) ${ }^{64}$ Indeed, confinement provided by suprafibrillar organization of collagen strongly impacts on the activity of mineralizing polymers. The results suggest the occurrence of sequential cooperative effects during the early stages of bone apatite precipitation through the formation of Ca-DMP1 complex, which then binds to collagen allowing the concentration of apatite ion precursors in gap regions. Formation of highly apatite nuclei and inhibition of both homogeneous nucleation and crystal growth are consistent with a common role of DMP1 being the control of physiological (versus pathological) bone formation. Strikingly, these effects are reached with the non-phosphorylated 57-KD amino-acids sequence under confinement. This versatile bone-like model will be useful to provide insights into the role of other bone components (e.g. citrate, proteoglycans or even different sequences related to NCPs kinetic of maturation (i.e. post-translation modification)) during the successive events that orchestrate mineralization. 


\section{ASSOCIATED CONTENT}

\section{Supporting Information}

The following files are available free of charge.

Composition of the solutions used to mineralize collagen matrices, SEM and TEM images, EDX spectra and TGA curves

\section{AUTHOR INFORMATION}

\section{Corresponding Author}

nadine.nassif@sorbonne-universite.fr

\section{Author Contributions}

The manuscript was written through contributions of all authors. All authors have given approval to the final version of the manuscript.

\section{ACKNOWLEDGMENT}

We thank C. Samson (Lille II University) for her pertinent advices to obtain the rpDMP1; O. Sel for discussion (LISE, SU); A. Anglo, C. Illoul, B. Haye (LCMCP, SU) for ultramicrotomy sections; I. Genois and P. Le Griel (LCMCP, SU) for help for SEM and TEM observations respectively; M. Selmane (IMPC, SU) for technical assistance in WAXD experiments, F.M. Fernandes (LCMCP, SU) for the 3D cholesteric scheme and A. Gloter (U-PSUD) for help with the acquisition of the intensity profile. 


\section{REFERENCES}

(1) Jackson S.F. The Fine Structure of Developing Bone in the Embryonic Fowl. Proc. R. Soc. London. Ser. B-Biol. Sci. 1957, 146 (923), 270-280.

(2) Weiner, S.; Traub, W. Organization of Hydroxyapatite Crystals within Collagen Fibrils. FEBS Lett. 1986, 206 (2), 262-266.

(3) Xu, Y. F.; Nudelman, F.; Eren, E. D.; Wirix, M. J. M.; Cantaert, B.; Nijhuis, W. H.; Hermida-Merino, D.; Portale, G.; Bomans, P. H. H.; Ottmann, C.; et al. Intermolecular Channels Direct Crystal Orientation in Mineralized Collagen. Nat. Commun. 2020, 11 (1), $1-12$.

(4) Landis, W. J.; Hodgens, K. J.; Song, M. J.; Arena, J.; Kiyonaga, S.; Marko, M.; Owen, C.; McEwen, B. F. Mineralization of Collagen May Occur on Fibril Surfaces: Evidence from Conventional and High-Voltage Electron Microscopy and Three-Dimensional Imaging. J. Struct. Biol. 1996, 117 (1), 24-35.

(5) Giraud-Guille, M.-M. Plywood Structures in Nature. Curr. Opin. Solid State Mater. Sci. 1998, 3 (3), 221-227.

(6) Garnero, P. The Role of Collagen Organization on the Properties of Bone. Calcif. Tissue Int. 2015, 97 (3), 229-240.

(7) Nassif, N.; Gobeaux, F.; Seto, J.; Belamie, E.; Davidson, P.; Panine, P.; Mosser, G.; Fratzl, P.; Giraud Guille, M. M. Self-Assembled Collagen-Apatite Matrix with Bone-like Hierarchy. Chem. Mater. 2010, 22 (11), 3307-3309.

(8) Wang, Y.; Azaïs, T.; Robin, M.; Vallée, A.; Catania, C.; Legriel, P.; Pehau-Arnaudet, G.; Babonneau, F.; Giraud-Guille, M. M.; Nassif, N. The Predominant Role of Collagen in the Nucleation, Growth, Structure and Orientation of Bone Apatite. Nat. Mater. 2012, 11 (8), 724-733.

(9) Hunter, G. K.; Goldberg, H. A. Nucleation of Hydroxyapatite by Bone Sialoprotein. Proc. Natl. Acad. Sci. U. S. A. 1993, 90 (18), 8562-8565.

(10) Frenkel-Mullerad, H.; Avnir, D. Sol-Gel Materials as Efficient Enzyme Protectors: Preserving the Activity of Phosphatases under Extreme PH Conditions. J. Am. Chem. Soc. 2005, 127 (22), 8077-8081.

(11) Weiner, S.; Wagner, H. D. The Material Bone: Structure-Mechanical Function Relations. Annu. Rev. Mater. Sci. 1998, 28 (1), 271-298.

(12) Reznikov, N.; Shahar, R.; Weiner, S. Bone Hierarchical Structure in Three Dimensions. Acta Biomater. 2014, 10 (9), 3815-3826.

(13) Kokubo, T.; Takadama, H. How Useful Is SBF in Predicting in Vivo Bone Bioactivity? Biomaterials 2006, 27 (15), 2907-2915.

(14) He, G.; Dahl, T.; Veis, A.; George, A. Nucleation of Apatite Crystals in Vitro by SelfAssembled Dentin Matrix Protein 1. Nat. Mater. 2003, 2 (8), 552-558. 
(15) Tartaix, P. H.; Doulaverakis, M.; George, A.; Fisher, L. W.; Butler, W. T.; Qin, C.; Salih, E.; Tan, M.; Fujimoto, Y.; Spevak, L.; et al. In Vitro Effects of Dentin Matrix Protein-1 on Hydroxyapatite Formation Provide Insights into in Vivo Functions. J. Biol. Chem. 2004, 279 (18), 18115-18120.

(16) George, A.; Sabsay, B.; Simonian, P. A. L.; Veis, A. Characterization of a Novel Dentin Matrix Acidic Phosphoprotein. Implications for Induction of Biomineralization. J. Biol. Chem. 1993, 268 (17), 12624-12630.

(17) Macdougall, M.; Gu, T. T.; Luan, X.; Simmons, D.; Chen, J. Identification of a Novel Isoform of Mouse Dentin Matrix Protein 1: Spatial Expression in Mineralized Tissues. $J$. Bone Miner. Res. 1998, 13 (3), 422-431.

(18) Feng, J. Q.; Ward, L. M.; Liu, S.; Lu, Y.; Xie, Y.; Yuan, B.; Yu, X.; Rauch, F.; Davis, S. I.; Zhang, S.; et al. Loss of DMP1 Causes Rickets and Osteomalacia and Identifies a Role for Osteocytes in Mineral Metabolism. Nat. Genet. 2006, 38 (11), 1310-1315.

(19) Lorenz-Depiereux, B.; Bastepe, M.; Benet-Pagès, A.; Amyere, M.; Wagenstaller, J.; Müller-Barth, U.; Badenhoop, K.; Kaiser, S. M.; Rittmaster, R. S.; Shlossberg, A. H.; et al. DMP1 Mutations in Autosomal Recessive Hypophosphatemia Implicate a Bone Matrix Protein in the Regulation of Phosphate Homeostasis. Nat. Genet. 2006, 38 (11), 1248-1250.

(20) Mäkitie, O.; Pereira, R. C.; Kaitila, I.; Turan, S.; Bastepe, M.; Laine, T.; Kröger, H.; Cole, W. G.; Jüppner, H. Long-Term Clinical Outcome and Carrier Phenotype in Autosomal Recessive Hypophosphatemia Caused by a Novel DMP1 Mutation. J. Bone Miner. Res. 2010, 25 (10), 2165-2174.

(21) Turan, S.; Aydin, C.; Bereket, A.; Akcay, T.; Güran, T.; Yaralioglu, B. A.; Bastepe, M.; Jüppner, H. Identification of a Novel Dentin Matrix Protein-1 (DMP-1) Mutation and Dental Anomalies in a Kindred with Autosomal Recessive Hypophosphatemia. Bone 2010, 46 (2), 402-409.

(22) Ye, L.; Mishina, Y.; Chen, D.; Huang, H.; Dallas, S. L.; Dallas, M. R.; Sivakumar, P.; Kunieda, T.; Tsutsui, T. W.; Boskey, A.; et al. Dmp1-Deficient Mice Display Severe Defects in Cartilage Formation Responsible for a Chondrodysplasia-like Phenotype. J. Biol. Chem. 2005, 280 (7), 6197-6203.

(23) Ye, L.; MacDougall, M.; Zhang, S.; Xie, Y.; Zhang, J.; Li, Z.; Lu, Y.; Mishina, Y.; Feng, J. Q. Deletion of Dentin Matrix Protein-1 Leads to a Partial Failure of Maturation of Predentin into Dentin, Hypomineralization, and Expanded Cavities of Pulp and Root Canal during Postnatal Tooth Development. J. Biol. Chem. 2004, 279 (18), 19141-19148.

(24) He, G.; Gajjeraman, S.; Schultz, D.; Cookson, D.; Qin, C.; Butler, W. T.; Hao, J.; George, A. Spatially and Temporally Controlled Biomineralization Is Facilitated by Interaction between Self-Assembled Dentin Matrix Protein 1 and Calcium Phosphate Nuclei in Solution. Biochemistry 2005, 44 (49), 16140-16148.

(25) Tsuji, T.; Onuma, K.; Yamamoto, A.; Iijima, M.; Shiba, K. Direct Transformation from Amorphous to Crystalline Calcium Phosphate Facilitated by Motif-Programmed Artificial Proteins. Proc. Natl. Acad. Sci. U. S. A. 2008, 105 (44), 16866-16870. 
(26) He, G.; Dahl, T.; Veis, A.; George, A. Dentin Matrix Protein 1 Initiates Hydroxyapatite Formation in Vitro. Connect. Tissue Res. 2003, 44 (1), 240-245.

(27) Gericke, A.; Qin, C.; Sun, Y.; Redfern, R.; Redfern, D.; Fujimoto, Y.; Taleb, H.; Butler, W. T.; Boskey, A. L. Different Forms of DMP1 Play Distinct Roles in Mineralization. J. Dent. Res. 2010, 89 (4), 355-359.

(28) Huang, J.; Wong, C.; George, A.; Kaplan, D. L. The Effect of Genetically Engineered Spider Silk-Dentin Matrix Protein 1 Chimeric Protein on Hydroxyapatite Nucleation. Biomaterials 2007, 28 (14), 2358-2367.

(29) He, G.; George, A. Dentin Matrix Protein 1 Immobilized on Type I Collagen Fibrils Facilitates Apatite Deposition in Vitro. J. Biol. Chem. 2004, 279 (12), 11649-11656.

(30) Beniash, E.; Deshpande, A. S.; Fang, P. A.; Lieb, N. S.; Zhang, X.; Sfeir, C. S. Possible Role of DMP1 in Dentin Mineralization. J. Struct. Biol. 2011, 174 (1), 100-106.

(31) Silvent, J.; Nassif, N.; Helary, C.; Azaïs, T.; Sire, J. Y.; Giraud-Guille, M. M. Collagen Osteoid-Like Model Allows Kinetic Gene Expression Studies of Non-Collagenous Proteins in Relation with Mineral Development to Understand Bone Biomineralization. PLoS One 2013, $8(2), 1-10$.

(32) Retana-Lobo, C.; Guerreiro-Tanomaru, J. M.; Tanomaru-Filho, M.; de Souza, B. D. M.; Reyes-Carmona, J. Non-Collagenous Dentin Protein Binding Sites Control Mineral Formation during the Biomineralisation Process in Radicular Dentin. Materials (Basel). 2020, $13(5)$.

(33) Gajjeraman, S.; Narayanan, K.; Hao, J.; Qin, C.; George, A. Matrix Macromolecules in Hard Tissues Control the Nucleation and Hierarchical Assembly of Hydroxyapatite. J. Biol. Chem. 2007, 282 (2), 1193-1204.

(34) Bedran-Russo, A. K.; Ravindran, S.; George, A. Imaging Analysis of Early DMP1 Mediated Dentine Remineralization. Arch. Oral Biol. 2013, 58 (3), 254-260.

(35) Qin, C.; Brunn, J. C.; Cook, R. G.; Orkiszewski, R. S.; Malone, J. P.; Veis, A.; Butler, W. T. Evidence for the Proteolytic Processing of Dentin Matrix Protein 1: Identification and Characterization of Processed Fragments and Cleavage Sites. J. Biol. Chem. 2003, 278 (36), 34700-34708.

(36) Qin, C.; Huang, B.; Wygant, J. N.; McIntyre, B. W.; McDonald, C. H.; Cook, R. G.; Butler, W. T. A Chondroitin Sulfate Chain Attached to the Bone Dentin Matrix Protein 1 NH2Terminal Fragment. J. Biol. Chem. 2006, 281 (12), 8034-8040.

(37) Silvent, J.; Sire, J. Y.; Delgado, S. The Dentin Matrix Acidic Phosphoprotein 1 (DMP1) in the Light of Mammalian Evolution. J. Mol. Evol. 2013, 76 (1-2), 59-70.

(38) Lu, Y.; Yuan, B.; Qin, C.; Cao, Z.; Xie, Y.; Dallas, S. L.; McKee, M. D.; Drezner, M. K.; Bonewald, L. F.; Feng, J. Q. The Biological Function of DMP-1 in Osteocyte Maturation Is Mediated by Its 57-KDa c-Terminal Fragment. J. Bone Miner. Res. 2011, 26 (2), 331-340.

(39) Deshpande, A. S.; Fang, P. A.; Zhang, X.; Jayaraman, T.; Sfeir, C.; Beniash, E. Primary Structure and Phosphorylation of Dentin Matrix Protein 1 (DMP1) and Dentin 
Phosphophoryn (DPP) Uniquely Determine Their Role in Biomineralization. Biomacromolecules 2011, 12 (8), 2933-2945.

(40) Ling, Y.; Rios, H. F.; Myers, E. R.; Lu, Y.; Feng, J. Q.; Boskey, A. L. DMP1 Depletion Decreases Bone Mineralization in Vivo: An FTIR Imaging Analysis. J. Bone Miner. Res. 2005, 20 (12), 2169-2177.

(41) Burgener, B.; Ford, A. R.; Situ, H.; Fayad, M. I.; Hao, J. J.; Wenckus, C. S.; Johnson, B. R.; Begole, E. A.; George, A. Biologic Markers for Odontogenic Periradicular Periodontitis. J. Endod. 2010, 36 (8), 1307-1310.

(42) Sato, S.; Hashimoto, J.; Usami, Y.; Ohyama, K.; Isogai, Y.; Hagiwara, Y.; Maruyama, N.; Komori, T.; Kuroda, T.; Toyosawa, S. Novel Sandwich ELISAs for Rat DMP1: AgeRelated Decrease of Circulatory DMP1 Levels in Male Rats. Bone 2013, 57 (2), 429-436.

(43) Bradt, J. H.; Mertig, M.; Teresiak, A.; Pompe, W. Biomimetic Mineralization of Collagen by Combined Fibril Assembly and Calcium Phosphate Formation. Chem. Mater. 1999, 11 (10), 2694-2701.

(44) Olszta, M. J.; Cheng, X.; Jee, S. S.; Kumar, R.; Kim, Y. Y.; Kaufman, M. J.; Douglas, E. P.; Gower, L. B. Bone Structure and Formation: A New Perspective. Mater. Sci. Eng. R Reports 2007, 58 (3-5), 77-116.

(45) Nudelman, F.; Pieterse, K.; George, A.; Bomans, P. H. H.; Friedrich, H.; Brylka, L. J.; Hilbers, P. A. J.; De With, G.; Sommerdijk, N. A. J. M. The Role of Collagen in Bone Apatite Formation in the Presence of Hydroxyapatite Nucleation Inhibitors. Nat. Mater. 2010, 9 (12), 1004-1009.

(46) Bradt J. H.; Mertig M.; Teresiak A.; Pompe W. Biomimetic Mineralization of Collagen by Combined Fibril Assembly and Calcium Phosphate Formation. Chem. Mater. 1999, 11 (10), 2694-2701.

(47) Gower, L. B. Biomimetic Model Systems for Investigating the Amorphous Precursor Pathway and Its Role in Biomineralization. Chem. Rev. 2008, 108 (11), 4551-4627.

(48) Glimcher, M. J.; Hodge, A. J.; Schmitt, F. O. Macromolecular Aggregation States in Relation to Mineralization: The Collagen-Hydroxyapatite System as Studied in Vitro. Proc. Natl. Acad. Sci. 1957, 43 (10), 860-867.

(49) Lee, D. D.; Glimcher, M. J. Three-Dimensional Spatial Relationship between the Collagen Fibrils and the Inorganic Calcium Phosphate Crystals of Pickerel (Americanus Americanus) and Herring (Clupea Harengus) Bone. J. Mol. Biol. 1991, 217 (3), 487-501.

(50) Brown, W. E.; Eidelman, N.; Tomazic, B. Octacalcium Phosphate as a Precursor in Biomineral Formation. Adv. Dent. Res. 1987, 1 (2), 306-313.

(51) Crane, N. J.; Popescu, V.; Morris, M. D.; Steenhuis, P.; Ignelzi, M. A. Raman Spectroscopic Evidence for Octacalcium Phosphate and Other Transient Mineral Species Deposited during Intramembranous Mineralization. Bone 2006, 39 (3), 434-442.

(52) Gobeaux, F.; Belamie, E.; Mosser, G.; Davidson, P.; Panine, P.; Giraud-Guille, M. M. Cooperative Ordering of Collagen Triple Helices in the Dense State. Langmuir 2007, 23 
(11), 6411-6417.

(53) Bergman, I.; Loxley, R. Two Improved and Simplified Methods for the Spectrophotometric Determination of Hydroxyproline. Anal. Chem. 1963, 35 (12), 1961-1965.

(54) Rhee, S. H.; Tanaka, J. Hydroxyapatite Formation on Cellulose Cloth Induced by Citric Acid. J. Mater. Sci. Mater. Med. 2000, 11 (7), 449-452.

(55) Marelli, B.; Ghezzi, C. E.; Barralet, J. E.; Nazhat, S. N. Collagen Gel Fibrillar Density Dictates the Extent of Mineralization in Vitro. Soft Matter 2011, 7 (21), 9898-9907.

(56) Knight, D. P.; Nash, L.; Hu, X. W.; Haffegee, J.; Ho, M.-W. In Vitro Formation by Reverse Dialysis of Collagen Gels Containing Highly Oriented Arrays of Fibrils. J. Biomed. Mater. Res. 1998, 41 (2), 185-191.

(57) Kokubo, T.; Takadama, H. How Useful Is SBF in Predicting in Vivo Bone Bioactivity? Biomaterials 2006, 27 (15), 2907-2915.

(58) Bonewald, L. F.; Harris, S. E.; Rosser, J.; Dallas, M. R.; Dallas, S. L.; Camacho, N. P.; Boyan, B.; Boskey, A. Von Kossa Staining Alone Is Not Sufficient to Confirm That Mineralization in Vitro Represents Bone Formation. Calcif. Tissue Int. 2003, 72 (5), 537547.

(59) Nassif, N.; Martineau, F.; Syzgantseva, O.; Gobeaux, F.; Willinger, M.; Coradin, T.; Cassaignon, S.; Azaïs, T.; Giraud-Guille, M. M. In Vivo Inspired Conditions to Synthesize Biomimetic Hydroxyapatite. Chem. Mater. 2010, 22 (12), 3653-3663.

(60) Dorozhkin, S. V.; Epple, M. Biological and Medical Significance of Calcium Phosphates. Angew. Chemie - Int. Ed. 2002, 41 (17), 3130-3146.

(61) Landis, W. J.; Glimcher, M. J. Electron Diffraction and Electron Probe Microanalysis of the Mineral Phase of Bone Tissue Prepared by Anhydrous Techniques. J. Ultrastruct. Res. 1978, 63 (2), 188-223.

(62) Matsumoto, M.; Miyake, T.; Noshi, H.; Kambara, M.; Konishi, K. Zeta Potential Studies on the Adsorption of Proteins on a Synthetic Hydroxyapatite. Colloids Surf. 1989, 40, 7784.

(63) Niu, L. N.; Jee, S. E.; Jiao, K.; Tonggu, L.; Li, M.; Wang, L.; Yang, Y. D.; Bian, J. H.; Breschi, L.; Jang, S. S.; et al. Collagen Intrafibrillar Mineralization as a Result of the Balance between Osmotic Equilibrium and Electroneutrality. Nat. Mater. 2017, 16 (3), 370378.

(64) Lucent, D.; Vishal, V.; Pande, V. S. Protein Folding under Confinement: A Role for Solvent. Proc. Natl. Acad. Sci. U. S. A. 2007, 104 (25), 10430-10434.

(65) Sarem, M.; Lüdeke, S.; Thomann, R.; Salavei, P.; Zou, Z.; Habraken, W.; Masic, A.; Shastri, V. P. Disordered Conformation with Low Pii Helix in Phosphoproteins Orchestrates Biomimetic Apatite Formation. Adv. Mater. 2017, 29 (35), 1-13.

(66) Wang, Y.; Von Euw, S.; Laurent, G.; Crevant, C.; Bonhomme-Coury, L.; Giraud-Guille, M. M.; Babonneau, F.; Nassif, N.; Azaïs, T. Impact of Collagen Confinement vs. Ionic 
Substitutions on the Local Disorder in Bone and Biomimetic Apatites. Mater. Horizons 2014, 1 (2), 224-231.

(67) Jee, S. S.; Culver, L.; Li, Y.; Douglas, E. P.; Gower, L. B. Biomimetic Mineralization of Collagen via an Enzyme-Aided PILP Process. J. Cryst. Growth 2010, 312 (8), 1249-1256.

(68) Thula, T. T.; Rodriguez, D. E.; Lee, M. H.; Pendi, L.; Podschun, J.; Gower, L. B. In Vitro Mineralization of Dense Collagen Substrates: A Biomimetic Approach toward the Development of Bone-Graft Materials. Acta Biomater. 2011, 7 (8), 3158-3169.

(69) Chen, L.; Jacquet, R.; Lowder, E.; Landis, W. J. Refinement of Collagen-Mineral Interaction: A Possible Role for Osteocalcin in Apatite Crystal Nucleation, Growth and Development. Bone 2015, 71, 7-16.

(70) Chow, W. Y.; Rajan, R.; Muller, K. H.; Reid, D. G.; Skepper, J. N.; Wong, W. C.; Brooks, R. A.; Green, M.; Bihan, D.; Farndale, R. W.; et al. NMR Spectroscopy of Native and in Vitro Tissues Implicates PolyADP Ribose in Biomineralization. Science 2014, 344 (6185), 742-746.

(71) Gautieri, A.; Pate, M. I.; Vesentini, S.; Redaelli, A.; Buehler, M. J. Hydration and Distance Dependence of Intermolecular Shearing between Collagen Molecules in a Model Microfibril. J. Biomech. 2012, 45 (12), 2079-2083.

(72) Fratzl, P.; Fratzl-Zelman, N.; Klaushofer, K. Collagen Packing and Mineralization. An xRay Scattering Investigation of Turkey Leg Tendon. Biophys. J. 1993, 64 (1), 260-266.

(73) Glimcher, M. J.; Krane, S. M. The Incorporation of Radioactive Inorganic Orthophosphate as Organic Phosphate by Collagen Fibrils in Vitro. Biochemistry 1964, 3 (2), 195-202.

(74) Kim, D.; Lee, B.; Thomopoulos, S.; Jun, Y. S. The Role of Confined Collagen Geometry in Decreasing Nucleation Energy Barriers to Intrafibrillar Mineralization. Nat. Commun. 2018, 9 (1), 962.

(75) Akiva, A.; Kerschnitzki, M.; Pinkas, I.; Wagermaier, W.; Yaniv, K.; Fratzl, P.; Addadi, L.; Weiner, S. Mineral Formation in the Larval Zebrafish Tail Bone Occurs via an Acidic Disordered Calcium Phosphate Phase. J. Am. Chem. Soc. 2016, 138 (43), 14481-14487.

(76) Mahamid, J.; Sharir, A.; Addadi, L.; Weiner, S. Amorphous Calcium Phosphate Is a Major Component of the Forming Fin Bones of Zebrafish: Indications for an Amorphous Precursor Phase. Proc. Natl. Acad. Sci. U. S. A. 2008, 105 (35), 12748-12753.

(77) Von Euw, S.; Wang, Y.; Laurent, G.; Drouet, C.; Babonneau, F.; Nassif, N.; Azaïs, T. Bone Mineral: New Insights into Its Chemical Composition. Sci. Rep. 2019, 9 (1), 1-11.

(78) Cho, G.; Wu, Y.; Ackerman, J. L. Detection of Hydroxyl Ions in Bone Mineral by SolidState NMR Spectroscopy. Science 2003, 300 (5622), 1123-1127.

(79) Glimcher, M. J. Bone: Nature of the Calcium Phosphate Crystals and Cellular, Structural, and Physical Chemical Mechanisms in Their Formation in Medical Mineralogy and Geochemistry Vol. 64 (eds Sahai, N. \& Schoonen, M. A. A.) 223-282 (Reviews in Mineralogy \& Geochemistry, 2006) 
(80) Engler, A. J.; Sen, S.; Sweeney, H. L.; Discher, D. E. Matrix Elasticity Directs Stem Cell Lineage Specification. Cell 2006, 126 (4), 677-689. 